\title{
Regional Methane Emission Estimation Based on Observed Atmospheric Concentrations (2002-2012)
}

\author{
Prabir K. PATRA \\ Department of Environmental Geochemical Cycle Research, JAMSTEC, Yokohama, Japan \\ CAOS, Graduate School of Science, Tohoku University, Sendai, Japan \\ Tazu SAEKI \\ Department of Environmental Geochemical Cycle Research, JAMSTEC, Yokohama, Japan \\ Edward J. DLUGOKENCKY \\ NOAA Earth System Research Laboratory, Colorado, USA \\ Kentaro ISHIJIMA \\ Department of Environmental Geochemical Cycle Research, JAMSTEC, Yokohama, Japan \\ Taku UMEZAWA
}

National Institute for Environmental Studies, Tsukuba, Japan

\begin{abstract}
Akihiko ITO
National Institute for Environmental Studies, Tsukuba, Japan

Department of Environmental Geochemical Cycle Research, JAMSTEC, Yokohama, Japan

Shuji AOKI, Shinji MORIMOTO
\end{abstract}

CAOS, Graduate School of Science, Tohoku University, Sendai, Japan

Eric A. KORT

University of Michigan, Michigan, USA

Andrew CROTWELL

NOAA Earth System Research Laboratory, Colorado, USA

CIRES, University of Colorado Boulder, Colorado, USA

Corresponding author: Prabir K. Patra, DEGCR/JAMSTEC,

3173-25 Showa machi, Kanazawa-ku, Yokohama 2360001,

Japan

E-mail: prabir@jamstec.go.jp

(C)2016, Meteorological Society of Japan 


\title{
Kunchala RAVI KUMAR
}

Arctic GRENE, National Institute of Polar Research, Tachikawa, Japan

Department of Environmental Geochemical Cycle Research, JAMSTEC, Yokohama, Japan

and

Takakiyo NAKAZAWA

CAOS, Graduate School of Science, Tohoku University, Sendai, Japan

(Manuscript received 11 July 2015, in final form 4 November 2015)

\begin{abstract}
Methane $\left(\mathrm{CH}_{4}\right)$ plays important roles in atmospheric chemistry and short-term forcing of climate. A clear understanding of atmospheric $\mathrm{CH}_{4}$ 's budget of emissions and losses is required to aid sustainable management of Earth's future environment. We used an atmospheric chemistry-transport model (JAMSTEC's ACTM) for simulating atmospheric $\mathrm{CH}_{4}$. A global inverse modeling system has been developed for estimating $\mathrm{CH}_{4}$ emissions from 53 land regions for 2002-2012 using measurements at 39 sites. An ensemble of 7 inversions is performed by varying a priori emissions. Global net $\mathrm{CH}_{4}$ emissions varied between 505-509 and 524-545 $\mathrm{Tg} \mathrm{yr}^{-1}$ during 2002-2006 and 2008-2012, respectively (ranges based on 7 inversion cases), with a step like increase in 2007 in agreement with atmospheric measurements. The inversion system did not account for interannual variations in $\mathrm{OH}$ radicals reacting with $\mathrm{CH}_{4}$ in the atmosphere. Our results suggest that the recent update of the EDGAR inventory (version 4.2FT2010) overestimated the global total emissions by at least $25 \mathrm{Tg} \mathrm{yr}^{-1}$ in 2010. The increase in $\mathrm{CH}_{4}$ emission since 2004 originated in the tropical and southern hemisphere regions, coinciding with an increase in non-dairy cattle stocks by $\sim 10 \%$ from 2002 (with 1056 million heads) to 2012, leading to $\sim 10$

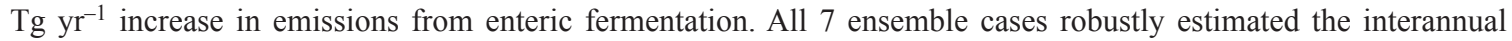
variations in emissions, but poorly constrained the seasonal cycle amplitude or phase consistently for all regions due to the sparse observational network. Forward simulation results using both a priori and a posteriori emissions are compared with independent aircraft measurements for validation. Based on the results of the comparison, we reject the upper limit $\left(545 \mathrm{Tg} \mathrm{yr}^{-1}\right)$ of global total emissions as $14 \mathrm{Tg} \mathrm{yr}^{-1}$ too high during 2008-2012, which allows us to further conclude that the increase in $\mathrm{CH}_{4}$ emissions over the East Asia (mainly China) region was 7-8 $\mathrm{Tg} \mathrm{yr}^{-1}$ between the 2002-2006 and 2008-2012 periods, contrary to $1-17 \mathrm{Tg} \mathrm{yr}^{-1}$ in the a priori emissions.
\end{abstract}

Keywords global and regional methane budget; chemistry-transport model; inverse model

\section{Introduction}

Methane $\left(\mathrm{CH}_{4}\right)$ is one of the most important shortlived climate forcers (SLCFs) along with tropospheric ozone and black carbon according to the United Nations Environment Programme. Reducing their emissions could improve public health, reduce losses in crop-yield, and slow the rate of near-term climate change (UNEP 2011). An assessment of the options for $\mathrm{CH}_{4}$ emission reduction remained uncertain due to the complex nature of $\mathrm{CH}_{4}$ emission and loss mechanisms. Methane is emitted in comparable amounts from natural and anthropogenic processes on the Earth's surface, and about $90 \%$ is lost in the troposphere by chemical reaction with hydroxyl $(\mathrm{OH})$ radicals (e.g., Fung et al. 1991; Hein et al. 1997; Patra et al. 2011; Kirschke et al. 2013; Ghosh et al. 2015). Anthropogenic emission inventories based on statistics of socio-economic activities from individual countries have several sources of uncertainties, such as, country-specific sectorial emission factors and timing of new technology implementation (Janssens-Maenhout et al. 2012). It is also believed that the statistics themselves is a considerable source of uncertainty, especially in developing countries where the statistics may be incomplete and/or unreliable 
(Liu et al. 2015). Methane emissions from natural and agricultural processes can be simulated by terrestrial ecosystem models, but estimates of these emissions suffer from uncertainties in parameterization of emission processes, distribution maps of source regions/ points and defining drivers of $\mathrm{CH}_{4}$ production (e.g., Etiope and Milkov 2004; Matthews and Fung 1987; Ringeval et al. 2010; Ito and Inatomi 2012; Bange et al. 2009). Inter-hemispheric distribution and interannual variation of $\mathrm{OH}$ are also ill-constrained by direct measurements or in chemistry-climate models (Montzka et al. 2011; Patra et al. 2014), and thus, they remain one of the main sources of uncertainty in global and regional budgets of atmospheric $\mathrm{CH}_{4}$.

Given these uncertainties in "bottom-up" emission inventories and atmospheric loss of $\mathrm{CH}_{4}$, our understanding of the budgets of this species in the Earth's environment remained limited. Here, we estimate $\mathrm{CH}_{4}$ emissions by inverse modeling ("top-down" approach) from atmospheric $\mathrm{CH}_{4}$ measurements and source-receptor relationships using forward chemistry-transport model (CTM) simulations. Noting the importance of $\mathrm{CH}_{4}$ in understanding Earth's chemistry-climate interactions, $\mathrm{CH}_{4}$ dry-air mole fractions are measured at an increasingly large number of sites since the early 1970s using gas chromatography (high accuracy; approximately $3 \mathrm{ppb}$ in $1750 \mathrm{ppb}$ ) (Khalil and Rasmussen 1983; Aoki et al. 1992; Dlugokencky et al. 2003; Cunnold et al. 2002). According to the World Data Centre for Greenhouse Gases (WDCGG; http://ds.data.jma.go.jp/ $\mathrm{gmd} / \mathrm{wdcgg}$ ), measurements at more than 100 surface sites and several aircraft flights were performed in 2010. Remote sensing retrievals of $\mathrm{CH}_{4}$ column-averaged mole fractions are available since 2009 from the dedicated Greenhouse gases Observing SATellite (GOSAT) and since 2002 using SCIAMACHY onboard the multipurpose satellite ENVISAT (Yoshida et al. 2011; Schneising et al. 2011). Although satellite retrievals are less accurate and less precise (approximately $1 \%$ random uncertainty; and encountering more problematic systematic biases), they have the potential to fill the large gaps in direct measurements, notably, over tropical regions and developing parts of Asia (e.g., Patra et al. 2003; Bergamaschi et al. 2013; Houweling et al. 2014). Forward and inverse modeling results of atmospheric $\mathrm{CH}_{4}$ have been key to understanding the dynamics of observed $\mathrm{CH}_{4}$ variations, e.g., the slowing down of the $\mathrm{CH}_{4}$ growth rate in the 1990s, the quasi-steady state during 1999-2006, and the renewed growth since 2007 (Dlugokencky et al. 2003, 2009; Steele et al. 1992; Rigby et al. 2008;
Bousquet et al. 2006, 2011; Patra et al. 2011).

Global or regional budgets of $\mathrm{CH}_{4}$ estimated by inverse modeling are also complex due to the incapability of separating collocated natural and anthropogenic emissions as well as uncertainties in modeling the loss processes in the Earth's atmosphere. Thus, we have simplified the $\mathrm{CH}_{4}$ budgeting system by optimizing net emissions (total emissions - soil sink) on land only and ignoring the interannual variations in loss processes due to $\mathrm{OH}, \mathrm{Cl}$ and $\mathrm{O}\left({ }^{1} \mathrm{D}\right)$. This $\mathrm{CH}_{4}$ inversion system is much simpler than inversions of atmospheric $\mathrm{CO}_{2}$, because $\mathrm{CO}_{2}$ has much more variability in surface fluxes due to fairly-balanced emissions and sinks with strong diurnal variation on top of the spatial heterogeneity. Recent studies have reported weak and contrasting diurnal variations in $\mathrm{CH}_{4}$ fluxes, e.g., always sink (Wang et al., 2013) or always source (Alberto et al. 2014), which are thus far ignored in modeling atmospheric $\mathrm{CH}_{4}$, to the best of our knowledge and in this study as well. A diurnal cycle of $\mathrm{CH}_{4}$ emissions is, however, much weaker than that of $\mathrm{CO}_{2}$ for which photosynthetic uptake during the daylight period is generally balanced by $\mathrm{CO}_{2}$ released during respiration within 24 hours. For $\mathrm{CH}_{4}$, the surface sink is less than $10 \%$ of the anthropogenic emission, while for $\mathrm{CO}_{2}$, photosynthetic uptake (gross primary productivity) is about 10 times greater than the anthropogenic emissions (e.g., Ito and Inatomi 2012; EDGAR42FT 2013). Thus, in addition to discussions on $\mathrm{CH}_{4}$ budgets, we will compare the $\mathrm{CH}_{4}$ inversions to $\mathrm{CO}_{2}$ inverse modeling. Such discussion is useful in terms of rapid increases in the both $\mathrm{CO}_{2}$ and $\mathrm{CH}_{4}$ emissions in association with a dramatic increase in the fossil fuel consumption from China since 2004 (EDGAR42FT 2013).

We estimated $\mathrm{CH}_{4}$ emissions for 2002-2012 using JAMSTEC's ACTM simulations and measurements of $\mathrm{CH}_{4}$ at selected 39 surface sites. A more sophisticated inversion system will be developed in the future for assimilating all available measurements. In Section 2, we describe the forward CTM setup and the development of a 53-region inverse model, followed by results and discussions in Section 3. We use independent datasets from aircraft campaigns and regular chartered flights for validating the $\mathrm{CH}_{4}$ emission inversion results. Conclusions are given in Section 4.

\section{Materials and method}

\subsection{Forward model setup}

Methane mole fractions are simulated using the Center for Climate System Research/National Institute for Environmental Studies/Frontier Research 
Center for Global Change (CCSR/NIES/FRCGC) atmospheric general circulation model (AGCM)based CTM (i.e., JAMSTEC's ACTM; Patra et al. 2009). ACTM is run at a horizontal resolution of T42 spectral truncations $\left(\sim 2.8 \times 2.8^{\circ}\right)$, and 67 sigma-pressure vertical levels. The following continuity equation is solved for time $(t)$ evolution of $\mathrm{CH}_{4}$ at different latitude $(y)$, longitude $(x)$ and altitude $(z)$ in the Earth's atmosphere.

$$
\begin{aligned}
& \frac{d \mathrm{CH}_{4}(x, y, z, t)}{d t}=S_{\mathrm{CH}_{4}}(x, y, t)-L_{\mathrm{CH}_{4}}(x, y, z, t) \\
& -\nabla \cdot \Phi_{\mathrm{CH}_{4}}(x, y, z, t),
\end{aligned}
$$

where,

$\mathrm{CH}_{4}=$ methane mole fraction in the atmosphere

$S=$ Emissions/sinks of $\mathrm{CH}_{4}$ at the surface, taken from bottom-up emission inventories and terrestrial ecosystem model simulations

$L=$ Temperature $(T)$ dependent loss rates of $\mathrm{CH}_{4}$ are given as

$$
\begin{aligned}
& \mathrm{CH}_{4}+\mathrm{O}\left({ }^{1} \mathrm{D}\right) \rightarrow \text { Products }\left(\mathrm{k}_{\mathrm{O}^{1} \mathrm{D}}=1.75 \times 10^{-10}\right) \\
& \mathrm{CH}_{4}+\mathrm{OH} \rightarrow \mathrm{CH}_{3}+\mathrm{H}_{2} \mathrm{O}\left(\mathrm{k}_{\mathrm{OH}}=2.45\right. \\
& \quad \times 10^{-12} \exp (-1775 / \mathrm{T}) \\
& \mathrm{CH}_{4}+\mathrm{Cl} \rightarrow \mathrm{CH}_{3}+\mathrm{HCl}\left(\mathrm{k}_{\mathrm{Cl}}=7.3\right. \\
& \quad \times 10^{-12} \exp (-1280 / T)
\end{aligned}
$$

Last term: defines transport of $\mathrm{CH}_{4}$ by advection, convection and diffusion

Two of the 3 terms (loss and transport) on the right-hand side (RHS) of Eq. (1) should be critically evaluated before optimizing the other term (emissions, $S$ ). The AGCM meteorology is nudged with horizontal winds $(U$ and $V$ ) and temperature from the Japan Meteorological Agency reanalysis fields, version JRA-25 (Onogi et al. 2007). Representation of inter-hemispheric transport in ACTM has been validated using a simulation of sulfur hexafluoride $\left(\mathrm{SF}_{6}\right)$, with an estimated exchange time of 1.39 years from remote surface measurements (Patra et al. 2011), and by comparison with aircraft measurements of latitude-altitude cross-sections over the Central Pacific (Patra et al. 2014).

The aforementioned chemical reaction rate constants are taken from the compilation of Chemical Kinetics and Photochemical Data for Use in Atmospheric Studies (Sander et al. 2006). Global mean OH is optimized using methyl chloroform $\left(\mathrm{CH}_{3} \mathrm{CCl}_{3}\right)$ by applying a single scaling factor of 0.92 to the seasonally varying $\mathrm{OH}$ field of Spivakovski et al. (2000).
This scaling factor is applied to simulate the observed $\mathrm{CH}_{3} \mathrm{CCl}_{3}$ decay rate in the troposphere in the period 2004-2011 (Patra et al. 2014). We have shown that this $\mathrm{OH}$ field represents a northern-to-southern hemispheric $(\mathrm{NH} / \mathrm{SH}) \mathrm{OH}$ ratio close to 1 , as suggested by the observed and modeled $\mathrm{CH}_{3} \mathrm{CCl}_{3}$ inter-hemispheric gradients, which is critical for unbiased estimation of surface emissions in the two hemispheres (Patra et al. 2014). Seasonally varying $\mathrm{OH}$ is repeated each year of the simulation (cyclostationary), hence ignoring inter-annual variability (IAV). Stratospheric $\mathrm{CH}_{4}$ losses due to reaction with $\mathrm{OH}, \mathrm{O}\left({ }^{1} \mathrm{D}\right)$, and chlorine $(\mathrm{Cl})$ radicals are calculated using their concentration fields simulated by the ACTM's stratospheric model run (Takigawa et al. 1999). We do not account for the reaction of $\mathrm{CH}_{4}$ with $\mathrm{Cl}$ radicals in the marine boundary layer as part of the tropospheric $\mathrm{CH}_{4}$ sink (Lassey et al. 2011 and references therein).

Since the large-scale transport and $\mathrm{OH}$ field are optimally balanced in ACTM, the model-observation mismatches in $\mathrm{CH}_{4}$ abundance at background sites can be assigned to error in bottom-up (or a priori) emissions by the inverse modeling at greater confidence than the version of ACTM without validated transport and $\mathrm{OH}$ fields. However, the coarse spatial resolutions of ACTM (T42 and only a few vertical layers within the planetary boundary layer) limit our ability to assimilate measurements near strong local sources, e.g., at continental sites.

\subsection{A priori emissions (sources) and loss}

We combined emissions from natural and anthropogenic activities, and subtracted the surface sinks due to bacterial consumption in the soil to prepare an ensemble of 7 cases of a priori emissions (ref. Fig. 1, and details later in this section). Six of them used different combinations of sectorial anthropogenic emissions from EDGAR42FT (2013), namely, agricultural soils $(4 \mathrm{C}+4 \mathrm{D})$, agricultural waste burning (4F), energy manufacturing transformation (1A1 $+1 \mathrm{~A} 2$ ), enteric fermentation (4A), fossil fuel fires (7A), fugitive from solid (1B1), oil production and refineries (1B2a), gas production and distribution (1B2B), industrial process and product use (2), manure management (4B), non-road transportation $(1 \mathrm{~A} 3 \mathrm{a}+\mathrm{c}+\mathrm{d}+\mathrm{e})$, residential (1A4), road transportation (1A3b), soil waste disposal $(6 \mathrm{~A}+6 \mathrm{C})$, and waste water (6B). The EDGAR42FT (2013) emission inventory (European Commission, Joint Research Centre (JRC)/Netherlands Environmental Assessment Agency (PBL)) is available as annual emissions at $0.1^{\circ} \times 0.1^{\circ}$ resolution for 2000-2010. Anthropogenic 


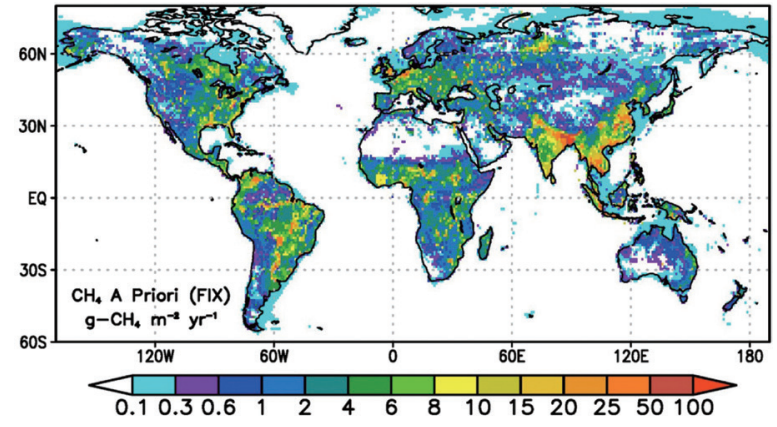

Fig. 1. An example map of annual mean $\mathrm{CH}_{4}$ emission distributions consisting of all the natural and anthropogenic emissions (Case $\mathrm{CH}_{4}$ fix).

emissions for 2011-2013 are kept constant at the level of 2010. The anthropogenic emissions are then added to biogenic emissions from (1) wetlands and rice paddies simulated by the VISIT terrestrial ecosystem model for 2000-2013 (Ito and Inatomi 2012), (2) biomass burning emissions from the Goddard Institute for Space Studies (GISS) $(\times 0.315)$ and Global Fire Emission Database version 3.2 (Fung et al. 1991; van der Werf 2010; following EXTRA scenario of TransCom- $\mathrm{CH}_{4}$, Patra et al. 2011) are added to those for termites (as in Fung et al. 1991), coastal ocean (Bange et al. 2009), and mud volcano (Etiope and Milkov 2004). This case is referred to as ' $\mathrm{CH}_{4} \mathrm{e} 42$ ' and the global total land emissions are shown in Fig. 2 (522 $\mathrm{Tg} \mathrm{yr}^{-1}$ in 2002; green line), which consists of $275,157,32,60,20,5$ and $-25 \mathrm{Tg} \mathrm{yr}^{-1}$ from total anthropogenic, wetlands, rice paddies, biomass burning, termites, mud volcano and soil oxidation, respectively.

Based on the forward ACTM simulation using $\mathrm{CH}_{4} \mathrm{e} 42$ emissions, as also pointed out in TransCom- $\mathrm{CH}_{4}$ simulations (Patra et al. 2011), we find that the model largely overestimates the observed $\mathrm{CH}_{4}$ growth rate after about 2005. It is difficult to envisage which emission sector needs to be modified to simulate the observed $\mathrm{CH}_{4}$ growth rate. Thus for the inversion, an ensemble of different a priori emission scenarios is proposed and we have formulated 6 other a priori cases (in addition to Case $1 . \mathrm{CH}_{4} \mathrm{e} 42$ described earlier).

Case 2. $\mathrm{CH}_{4}$ ags: all emission sectors in EDGAR42FT kept constant at the values for 2000, except for the emissions from agricultural soils $(4 \mathrm{C}+$ 4D).

Case 3. $\mathrm{CH}_{4}$ efm: Same as $\mathrm{CH}_{4}$ ags, but change emissions only from Enteric fermentation (4A).

Case 4. $\mathrm{CH}_{4}$ fug: Same as $\mathrm{CH}_{4}$ ags, but change emissions only from Fugitive from solid fuel (1B1). Note that this emission sector within China is one of the main causes of global total emission increase in Case $\mathrm{CH}_{4} \mathrm{e} 42$ (ref. Fig. 2).

Case 5. $\mathrm{CH}_{4}$ ong: Same as $\mathrm{CH}_{4}$ ags, but change emissions only from Oil production and refineries (1B2a), Gas production and distribution (1B2B).

Case 6. $\mathrm{CH}_{4} \mathrm{fix}$ : all the EDGAR42FT emission sectors kept constant at the values for 2000 (Fig. 1).

Case 7. $\mathrm{CH}_{4}$ ctl: Same as the Control emission scenario of TransCom- $\mathrm{CH}_{4}$ experiment, with following differences from 6 earlier cases; the EDGAR32FT anthropogenic emissions (as in Patra et al. 2011), and the GISS wetland and biomass burning emissions from Fung et al (1991), and emissions from rice paddies (Yan et al. 2009). The global land emission for the case $\mathrm{CH}_{4} \mathrm{ctl}$ is kept constant at $509.8 \mathrm{Tg} \mathrm{yr}^{-1}$.

Interannual variations in $\mathrm{CH}_{4}$ a priori emissions are mainly caused by wetland and rice paddy (VISIT) and biomass burning (GFED) sectors, which are common for the first 6 ensemble members (except for $\mathrm{CH}_{4} \mathrm{ctl}$ ) as evident from Fig. 2a.

\subsection{Inverse model setup}

The imbalance between a priori emissions and loss rates (ref. Fig. 2) results in the observed growth in $\mathrm{CH}_{4}$ burden in the Earth's atmosphere. Since the ACTM forward simulations using a priori emissions do not adequately match the measurements within the instrumental and transport model uncertainties, inverse model calculations are performed to rectify deficiencies in bottom-up emission estimates. Our inversion system is based on Rayner et al. (1999) and Patra et al. (2003) for $\mathrm{CO}_{2}$, with a couple of modifications on divisions of land-only regions and treatment of the a priori (presubtraction) model as discussed later. We have chosen not to optimize $\mathrm{CH}_{4}$ emissions from the ocean regions due to its small contribution $\left(\sim 10 \mathrm{Tg} \mathrm{yr}^{-1}\right)$ to the global total emission. In the Bayesian method, we estimated emissions (S) and their uncertainties $\left(\mathrm{C}_{\mathrm{S}}\right)$ for 53 basis land regions (Fig. 3) using the following equations:

$$
\begin{aligned}
& C_{S}=\left(G^{T} C_{D}^{-1} G+C_{S_{0}}^{-1}\right)^{-1} \\
& S=S_{0}+\left(G^{T} C_{D}^{-1} G+C_{S_{0}}^{-1}\right)^{-1} G^{T} C_{D}^{-1}\left(D-D_{A C T M}\right) \\
& S_{0}=\text { regional prior sources } \\
& C_{S_{0}}=\text { Prior source covariance (square of uncer- }
\end{aligned}
$$



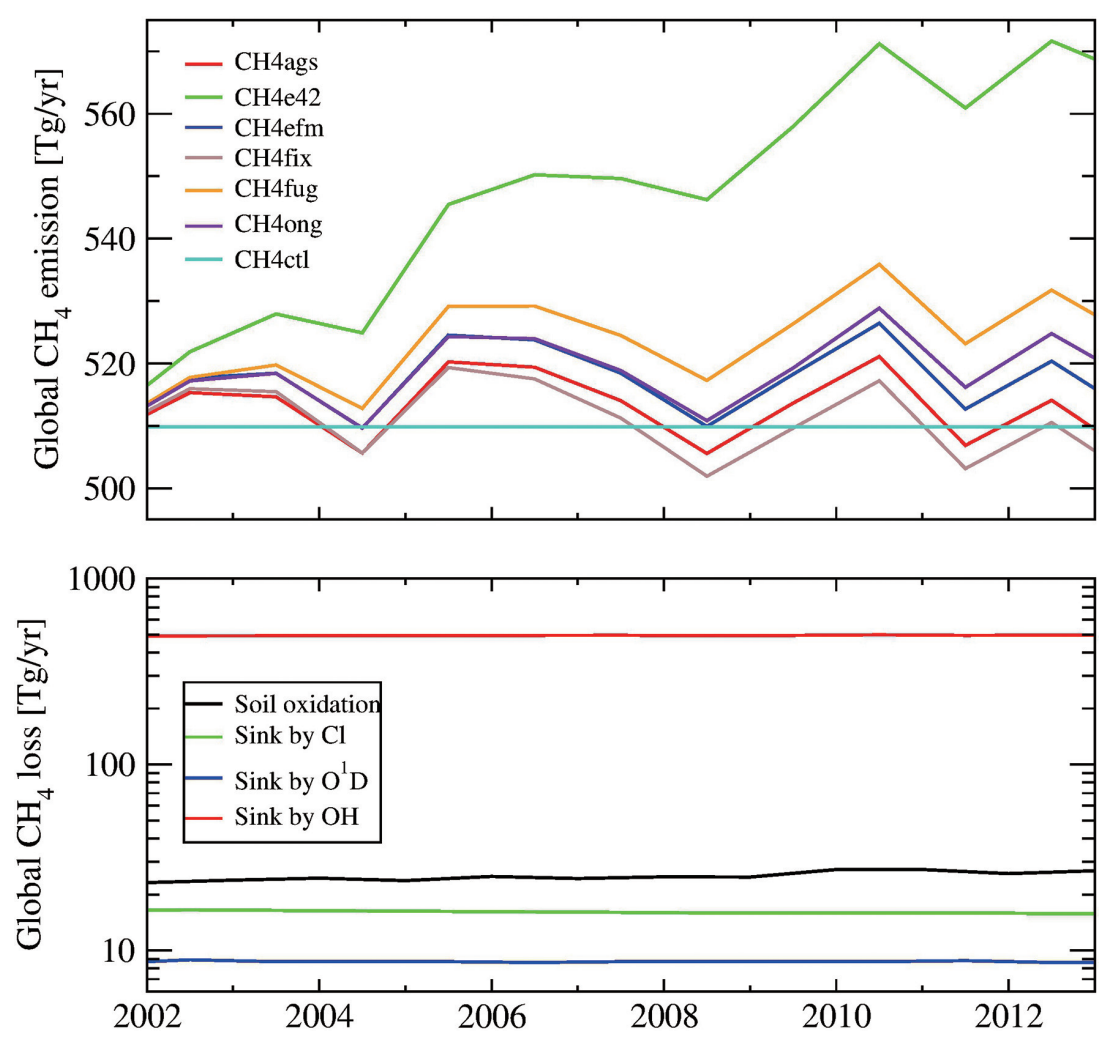

Fig. 2. Global total 'land' emissions for 7 different a priori emission cases (a; top panel) and losses in ACTM simulation for the emission case $\mathrm{CH}_{4}$ fix (b; bottom panel). Note that emissions over the ocean regions are not included in the emission time series and inversion results.

tainty), set at $70 \%$ of region-total emission for each month $\left(S_{0}\right)$

$D=$ atmospheric observations

$C_{D}=$ data covariance and set to variable (ref. Section 2.4)

$D_{A C T M}=$ ACTM simulation using a priori emissions $\left(S_{0}\right)$. Also referred to as presubtraction concentrations

$G=$ Green's functions, defining the regional source-receptor (concentration at sites) relationships

Unlike $\mathrm{CO}_{2}$ inversions, we simulated $\mathrm{CH}_{4}$ mole fractions $\left(D_{A C T M}\right)$ continuously from the beginning to the end of the inversion period (01 January 2001 - 31 December 2013) and calculated model-measurement differences $\left(D-D_{A C T M}\right)$. For $\mathrm{CO}_{2}$ inversion, a monthly pulse is simulated for 3-4 years starting from 1 st of the 12 months each for every year of inversion (Rayner et al. 1999). Our method is valid only when the simulated growth rates using a priori emissions are in close agreement with the observed growth rate, and also helps to linearize the emission-concentration relationships somewhat because $\mathrm{CH}_{4}$ in the atmo- sphere undergoes the chemical loss. This method is efficient for testing diverse cases of a priori emission scenarios at an affordable computing resource. ACTM is spun up for 13 years (until 31 December 2000, 24 UT) before starting the 7 ensemble simulations with different a priori emissions.

To linearize the system further, regional basis functions are calculated as the difference between a background $\mathrm{CH}_{4}$ tracer with seasonally varying emission (no interannual variations) and the background plus a unitary regional emission basis function. We used 53 regional basis functions of $1 \mathrm{Tg}^{-1} r^{-1}$, prepared from the annual mean map of the background $\mathrm{CH}_{4}$ tracer $\left(\mathrm{CH}_{4} \mathrm{ctl}\right)$. The basis emission functions are assumed the same for all 7 ensemble inversion cases and all years. Only one G-matrix is constructed using the meteorology of 2009 for a decay period of 59 months following 1 month of pulse emission. Thus our inversion system uses quasi-interannually varying winds (IAV for presubtracted runs, but cyclostationary for basis functions). With the continuous simulation of 


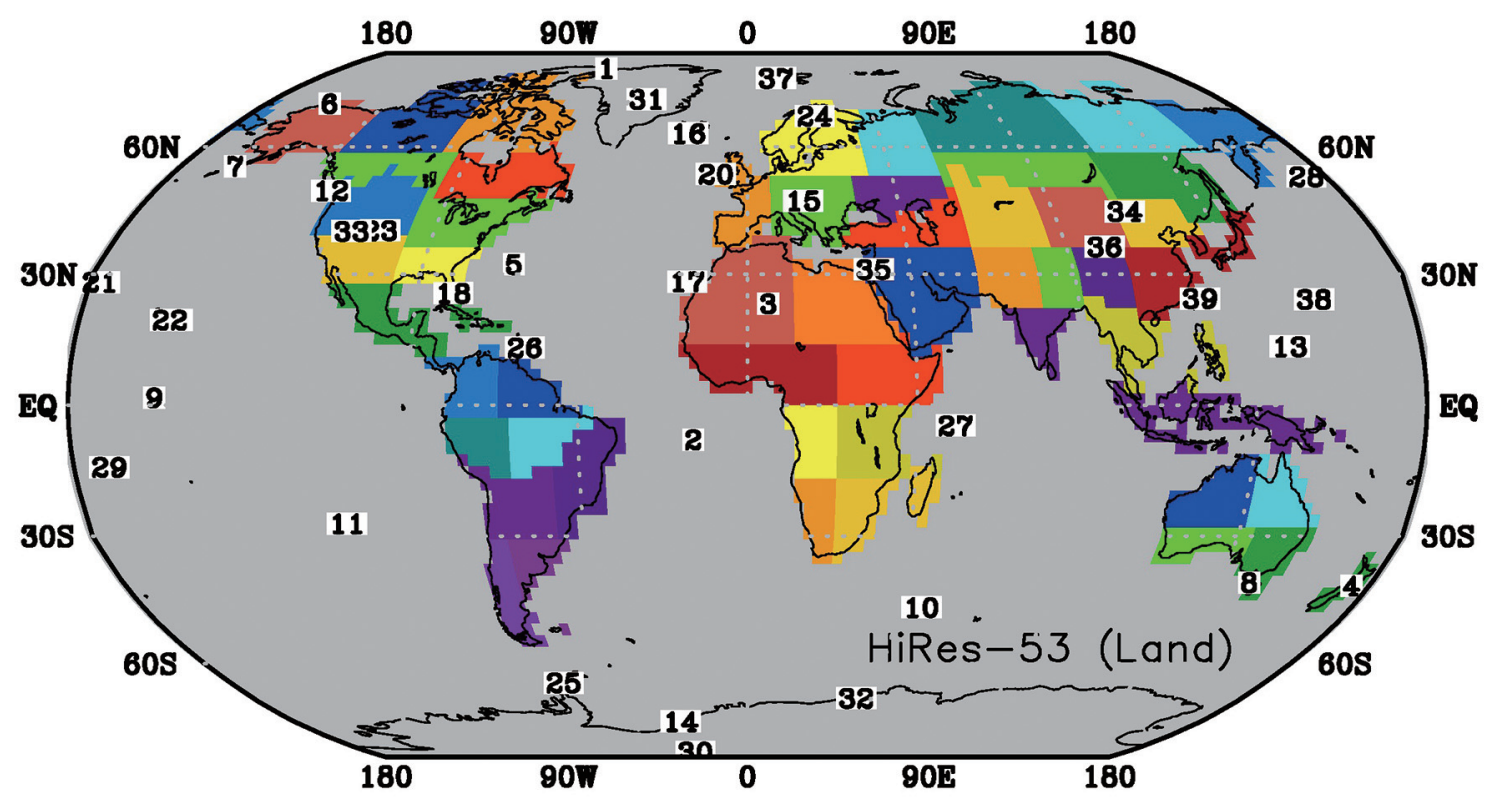

Fig. 3. 53 land regions of $\mathrm{CH}_{4}$ emission inversion (colour shaded), and locations of 39 measurement stations identified by numbers (see Appendix for details of the site locations).

the presubtraction concentration $\left(D_{A C T M}\right)$, the routine extension of the inversion calculation to more recent years is relatively easy. A 13-year (2001-2013) block is computed at once to estimate monthly-mean $\mathrm{CH}_{4}$ emission corrections to the 53 basis regions of the inverse model. We analyze the results for 2002-2012 to avoid the "edge effect" (spin-up and spin-down years) in matrix inversion system employing singular value decomposition (SVD).

\subsection{Atmospheric measurements ( $D$ and $C_{D}$ )}

We use atmospheric $\mathrm{CH}_{4}$ measurements in units of dry-air mole fraction (in ppb, parts per billion) from 37 NOAA cooperative global air sampling network sites and 2 JMA sites for estimating monthly-mean emissions by inversion. The details of the sites are shown in Appendix and Fig. 3. Both measurement networks reported data on the WMO mole fraction scale (Dlugokencky et al. 2005) and are available on the WDCGG website. These measurement sites are chosen on the basis of minimal data gap, typically less than 2 months, for the period of inverse calculation, 2001-2013. We also limited the sites to remote/ marine locations only because the coarse ACTM resolution does represent well the continental sites near strong emission (Patra et al. 2009). Gaps of one month are filled by linear interpolation between two neighbouring months on either side of the missing data. The monthly-mean measurements are assigned data uncertainty $\left(\sqrt{C_{D}}\right)$ of $5 \mathrm{ppb}$ for measurement and model transport errors + residual standard deviations (RSDs) for site representation error due to coarse ACTM resolution. Monthly-mean RSD is calculated from the differences between the model simulated daily concentrations and a fitted curve (Nakazawa et al. 1997). The fitted curves and long-term trends for each daily average time series are derived using a Butterworth filter of order 16 with a cut-off length of 24 months and with 3 harmonics. ACTM simulated results are sampled at the nearest model grid from output at 3-hourly average values. The difference between the locations of model grid and measurement site leads to a model representation error, which is assumed to be proportional to the short-term (daily) temporal variability in simulated concentrations (see also Patra et al. 2003). These short-term variations in simulations result from heterogeneity in emission distributions, e.g., the RSDs are calculated to be $\sim 4.6$ and $\sim 18.5 \mathrm{ppb}$ at Mauna Loa $\left(156^{\circ} \mathrm{W}, 19^{\circ} \mathrm{N}\right)$ and Hungary $\left(17^{\circ} \mathrm{E}, 47^{\circ} \mathrm{N}\right)$, respectively.

For validation of the meridional $\mathrm{CH}_{4}$ gradients in the lower-middle troposphere, we use 2 datasets from aircraft profile measurements, since measurements in the lower-middle troposphere contain integrated 
source/sink signals from subcontinent or semi-hemisphere regions. The first of these datasets are $\mathrm{CH}_{4}$ mole fractions obtained by five HIPPO (HIAPER Pole to Pole Observations) aircraft campaigns during January 2009 - September 2011, covering all 4 seasons over the Central Pacific Ocean (Wofsy et al. 2011). In HIPPO, continuous $\mathrm{CH}_{4}$ measurements made using a quantum cascade laser spectrometer (QCLS) operated by Harvard University. We sampled ACTM simulations by linear interpolation in space and time from 3-dimentional model output at hourly time intervals. The second of these datasets are long-term vertical profiles measured over Sendai $\left(38.3^{\circ} \mathrm{N}, 140.9^{\circ} \mathrm{E}\right)$ by Tohoku University (Umezawa et al. 2014). These measurements are located strategically in the region of maximum emission increase due to anthropogenic activities as suggested by the inventory emissions. We take this opportunity to validate the emission trends estimated by inverse modeling through a comparison of trends in simulated and measured $\mathrm{CH}_{4}$ growth rates. This $\mathrm{CH}_{4}$ dataset is converted from the Tohoku University $\mathrm{CH}_{4}$ scale (Aoki et al. 1992) to the WMO mole fraction scale using $\mathrm{WMO}=0.98571 \mathrm{TU}+23.0402$ (correlation coefficient, $r^{2}=0.999969$ ) according to the results of WMO international standards comparisons (www. esrl.noaa.gov/gmd/ccgg/wmorr/wmorr_results.php?r$\mathrm{r}=\mathrm{rr} 5$ \& param $=\mathrm{CH} 4)$. This scale conversion produces offset range of 2-5 ppb for tropospheric $\mathrm{CH}_{4}$.

\section{Results and discussion}

We have performed several cases of inversions by varying a priori data uncertainty $\left(C_{D}\right)$ and emission uncertainties $\left(C_{S_{0}}\right)$. Here we present the results for $C_{D}=5 \mathrm{ppb}+\mathrm{RSD}$, and $C_{S_{0}}=S_{0} \times 0.7$. This case is selected based on $x^{2}$ value of close to 1 for a typical inverse model cases, e.g., $x^{2}$ is calculated to be 0.78 , 0.98 and 1.44 for $\mathrm{CH}_{4}$ ags, $\mathrm{CH}_{4}$ ctl and $\mathrm{CH}_{4} \mathrm{e} 42$, respectively. $x^{2}$ is the quadratic sum of the prior-posterior emissions differences weighted by the prior emission variances and the quadratic sum of the modeled-observed concentration differences weighted by the observation variances. Lower (higher) values of a priori data and emission uncertainties increase (decrease) the value of $x^{2}$.

\subsection{Simulated $\mathrm{CH}_{4}$ by forward and inverse models}

Figure 4 compares $\mathrm{CH}_{4}$ at 4 representative sites, namely, at northern high latitude (a. Alert), remote mountain (b. Walliguan), southern Japan island (c. Yonagunijima) and monsoon dominated Indian Ocean (d. Seychelles). At Alert, a remote site, the
$\mathrm{CH}_{4}$ variations are mostly controlled by the net balance between emissions and loss at the seasonal time scale and transport of $\mathrm{CH}_{4}$ from mid-latitudes to the arctic region. In each hemisphere, seasonality in loss of $\mathrm{CH}_{4}$ exceeds that of emissions, thus there is less atmospheric $\mathrm{CH}_{4}$ in summer than in winter at remote background sites. Observations at Walliguan show no clear (dampened) seasonal cycle suggesting local to regional influence on observed $\mathrm{CH}_{4}$. This site receives relatively lower $\mathrm{CH}_{4}$ concentration from the southwestern side and from the upper troposphere in the winter, and relatively higher $\mathrm{CH}_{4}$ concentrations from the east during the summer (Zhou et al. 2003; see also Fig. 1 and Patra et al. 2009). Yonagunijima observes pristine marine air during summer and emission signals from continental East Asia during the winter (Wada et al. 2011), thereby a deeper seasonal cycle compared to that at Alert. The measurements at Seychelles are influenced by the emissions over the Indian subcontinent during the northeast monsoon season (November to March), which otherwise represent the SH marine air (Patra et al. 2009). The comparison suggests ACTM simulation using a priori (inventory) emission is too high in the early 2000 s at all sites and somewhat in agreement with observed $\mathrm{CH}_{4}$ concentrations in recent years (grey line in Fig. 4). These differences tend to become zero, i.e., within the given data uncertainties for each site and month, after performing the inversion (red line). Note that these sites are used in inversions, and are not presented as independent validation but are depicted here to show the overall capability of the newly developed inversion system at JAMSTEC in fitting the observed time series.

\subsection{Emission uncertainty in the inverse model}

We assigned monthly varying a priori uncertainties to each of the 53 basis regions, and the Bayesian inversion system returned a posteriori uncertainty $\left(C_{S}\right)$ along with the corrections to regional emissions ( 2 nd term on the RHS of Eq. 3). Figure 5 shows maps of annual mean a priori uncertainties and the uncertainty reductions ([prior - poste]/[prior + poste] $/ 2$; in $\%)$. The uncertainty reduction is a measure of how strongly measurements record emission signals from the basis regions. Regions containing measurement sites are most strongly constrained, e.g., Temperate North America, Western Europe, East Asia and Northeast Africa. Emissions in Eastern Europe and Northeast Africa are moderately constrained by the measurements at sites located downwind. Most regions are weakly constrained by the 39 sites used 

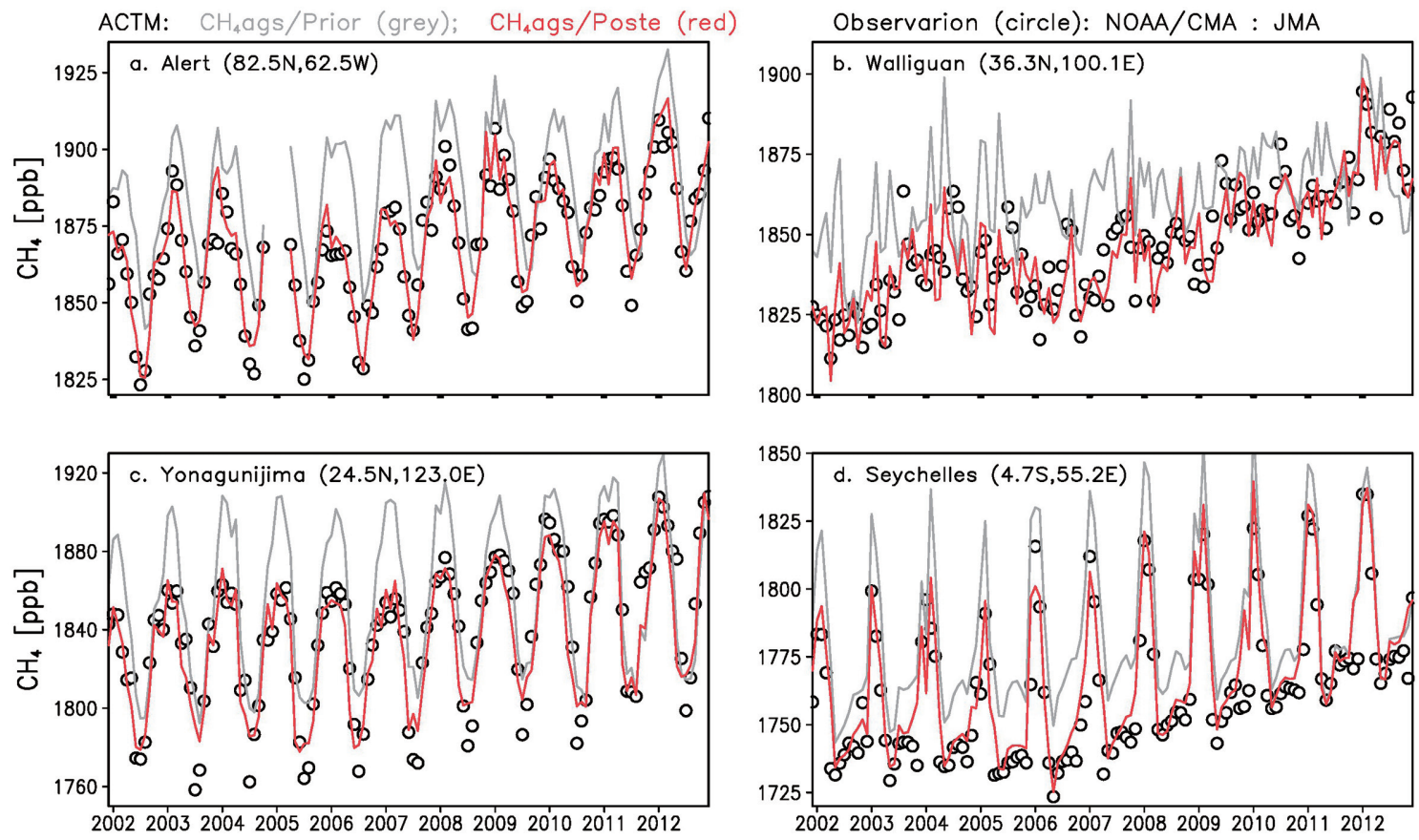

Fig. 4. Comparisons of ACTM simulated $\mathrm{CH}_{4}$ for prior emissions (grey; $D_{A C T M}$ ) and a posteriori $D_{A C T M}$ (red; case $\mathrm{CH}_{4}$ ags) with measurements by NOAA and JMA. Variable y-axis ranges are used to show variations at the sites as clearly as possible.

in the inverse model. This geographical extent of the constraint is critical for interpretation of the a posteriori emissions. We expect the inversion system to constrain the meridional gradient in emissions, because the regional emissions are well-mixed zonally and vertically within about a week. As a result, emission signals combined from all regions within the same latitude band will be captured at the remote marine sites. However, emissions from 53 basis regions may not be discussed individually at high level of confidence. For example, most parts of Boreal Asia and Boreal North America are not strongly constrained by the inversion, and thus emissions in the two boreal regions, on two different continents, are not likely separable. This is because all emission signals are propagated vertically upward and along the isentropes first, and then make several rounds zonally in the troposphere (thereby loosing distinction between origins) before reaching the background measurement sites at similar latitudes. For example, basis function signals from the nearest northeastern Siberia region first appeared at Shemya Island $\left(174^{\circ} \mathrm{E}\right.$, $53^{\circ} \mathrm{N}$ ) after 10 and 15 days of model run for January and July, respectively.

\subsection{Sub-hemispheric $\mathrm{CH}_{4}$ emissions}

Figure 6a shows the time evolution of global total $\mathrm{CH}_{4}$ emissions for the 7 inversion cases. It is observed that 6 of the 7 inversion ensembles agreed very well for the global totals and interannual variations $\left(\mathrm{r}^{2}=0.81\right.$ for $\mathrm{CH}_{4}$ ags and $\mathrm{CH}_{4} \mathrm{e} 42, \mathrm{r}^{2}>0.97$ between $\mathrm{CH}_{4}$ ags and 6 others). In line with the observed change in growth rate after the quasi-steady state during 1999-2006 (Rigby et al. 2008; Dlugokencky et al. 2009), the inversions show significant increases in the global $\mathrm{CH}_{4}$ flux starting in 2007 by greater than $20 \mathrm{Tg} \mathrm{yr}^{-1}$ compared to $\sim 12 \mathrm{Tg} \mathrm{yr}^{-1}$ of $1-\sigma$ standard deviation for IAV. The $\mathrm{CH}_{4}$ ctl case generated interannual variation that does not exist in the prior (grey straight line). Five other inversion results except for $\mathrm{CH}_{4} \mathrm{e} 42$ followed very similar emission trajectories despite their spread in a priori global totals for different years. In contrast, it is puzzling that the inversion case $\mathrm{CH}_{4} \mathrm{e} 42$, with the very high rate of a priori emission increase, remained separated compared to the other 6 inversion cases.

Figure $6 \mathrm{~b}-\mathrm{c}$ shows aggregated emissions for the northern extratropics (Boreal and Temperate North America, Europe, Boreal Asia and East Asia), tropics (Tropical South America, Northern Africa, South Asia 
(a) Uncertainty $\left(\mathrm{Tg}-\mathrm{CH}_{4} \mathrm{yr}^{-1}\right)$

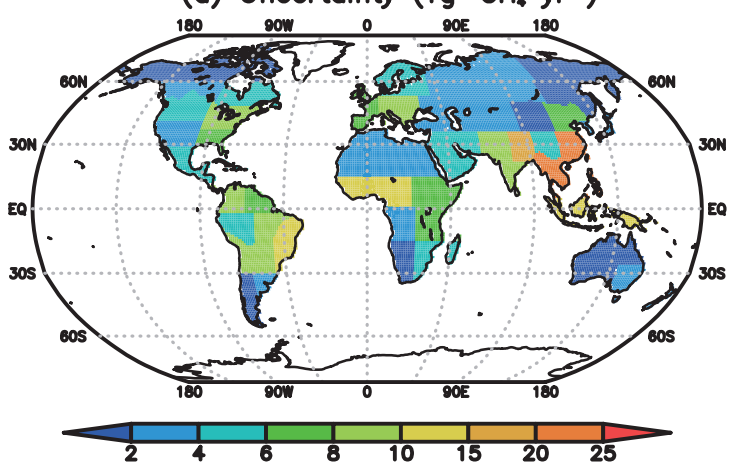

(b) Reductions (\%)

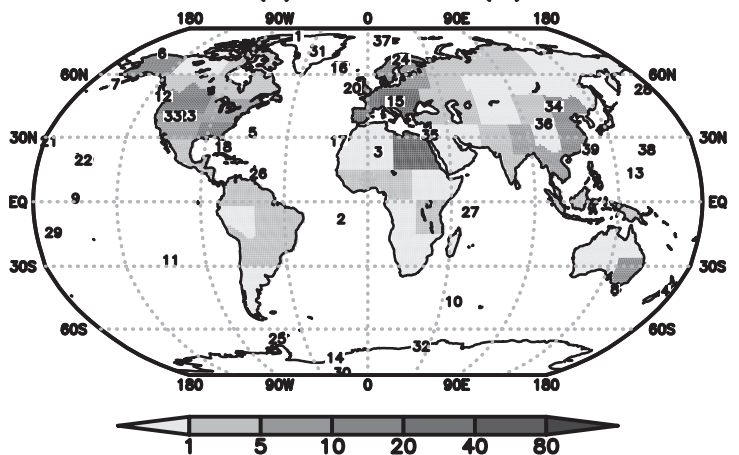

Fig. 5. Regional a priori uncertainties (a; left; $\left.S_{0} \times 0.7\right)$ and uncertainty reductions (b; right; case $\left.\mathrm{CH}_{4} a g s\right)$ are depicted in the left and right columns, respectively. Measurement site locations are marked by numbers in panel $b$.
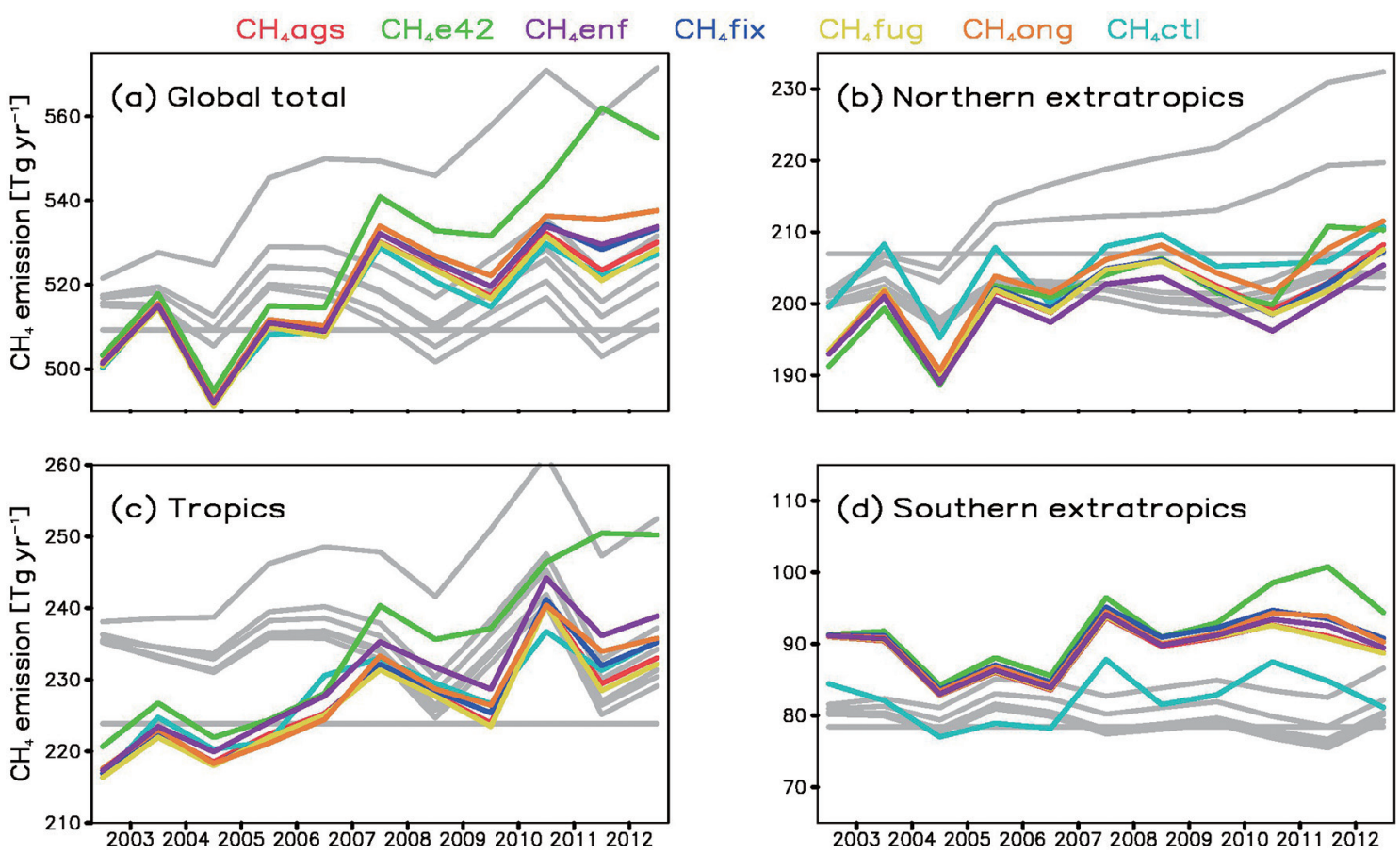

Fig. 6. Annual mean terrestrial $\mathrm{CH}_{4}$ emissions as estimated by 7 different inversion cases $\left(\mathrm{CH}_{4}\right.$ ags $-\mathrm{red}, \mathrm{CH}_{4} \mathrm{e} 42$ - green, $\mathrm{CH}_{4}$ enf - blue, $\mathrm{CH}_{4}$ fix - yellow, $\mathrm{CH}_{4}$ fug - orange, $\mathrm{CH}_{4}$ ong - purple and $\mathrm{CH}_{4} 4 \mathrm{tl}$ - cyan), in comparison with the a priori emissions (grey lines). The a priori values in panel (a) are the same as those in Fig. 2. The prior values for sub-regions should be intuitively interpreted with $\mathrm{CH}_{4}$ fix being at the bottom and $\mathrm{CH}_{4} \mathrm{e} 42$ at the top of 6 ensembles, whereas the case of $\mathrm{CH} 4 \mathrm{ctl}$ remained constant in time. Figures 8 and 9 also follow this convention.

and Southeast Asia) and southern extratropics (South America, Southern Africa and Oceania/Australasia) semi-hemispheric regions, respectively. All regions showed the lowest emission in 2004 and a complicated time evolution after that. The $\mathrm{NH}$ emissions increased only until 2008, followed by a decrease during 2009 and 2010, and then an increase until 2012. This time evolution is contrary to the a priori emission scenarios (either small or no variations to strong increase in emissions from about 200 to 230 
$\mathrm{Tg}^{-1} \mathrm{r}^{-1}$. Emissions from the tropics increased during 2002-2007 and remained relatively stable afterwards, with very strong IAVs, suggesting that emissions in the tropical region are under the control of natural climate variations, such as the El Niño Southern Oscillation (ENSO). The positive ENSO phases in 2002-03, 2006-2007 and 2009-2010 led to increased $\mathrm{CH}_{4}$ emissions from biomass burning in the Equatorial Asia and SH South America (van der Werf 2010; Patra et al. 2011; updated results, www.globalfiredata. org/tables.html). Emissions from the $\mathrm{SH}$ showed a decrease between 2002-2003 and 2004-2006, and then a step like increase in 2007 by about $8 \mathrm{Tg} \mathrm{yr}^{-1}$, followed by almost constant emissions until 2012 . The sustained emission increase in the $\mathrm{SH}$ is due to anthropogenic activities (addressed in Section 3.8). It is encouraging that the inversion system with only 39 sites can generate these changes in emissions fairly consistently, confirming that the remote marine sites do constrain integrated emissions from inverse model regions in Africa, America and Asia continents.

\subsection{Sub-continental scale $\mathrm{CH}_{4}$ emissions}

To further probe the inverse modeling results, $\mathrm{CH}_{4}$ emissions for 12 aggregated regions are discussed. Figure 7 shows a map of regional total emissions, in which it is obvious that there are stronger emissions from all tropical regions and populous temperate regions of North America and Europe. The regional total emissions averaged over the starting (20022006) and ending (2008-2012) 5-year periods of the inversion are given in Table 1 for checking systematic change in regional emissions. Mean emissions from Boreal North America, Temperate North America, Boreal Asia, Europe, Southern Africa and Australasia do not show a large increase or decrease in $\mathrm{CH}_{4}$ emission (changed by $+0.2,-0.7,-0.1,-1.4,+0.8$, and $-0.4 \mathrm{Tg} \mathrm{yr}^{-1}$, respectively). However, East Asia, West (South) Asia, Southeast Asia, Tropical South America, Temperate South America and Northern Africa showed greater increases of 9.0, 2.9, 4.7, $2.8,4.3$ and 2.4 , respectively, from 2002-2006 to 2008-2012 (6 year interval between the two averaging periods). The emission increase over East Asia requires a special mention; since the greatest emission increase rate of $\sim 17 \mathrm{Tg} \mathrm{yr}^{-1}$ in the a priori $\mathrm{CH}_{4} \mathrm{e} 42$ case was found. All inversion cases estimated that the emission increase in East Asia should be in the range $7-8 \mathrm{Tg} \mathrm{yr}^{-1}$ in this 6-year time interval. This result is in agreement with the results obtained by independent studies focusing on the East Asia region. Tohjima et al. (2014) estimated annual $\mathrm{CH}_{4}$ emissions

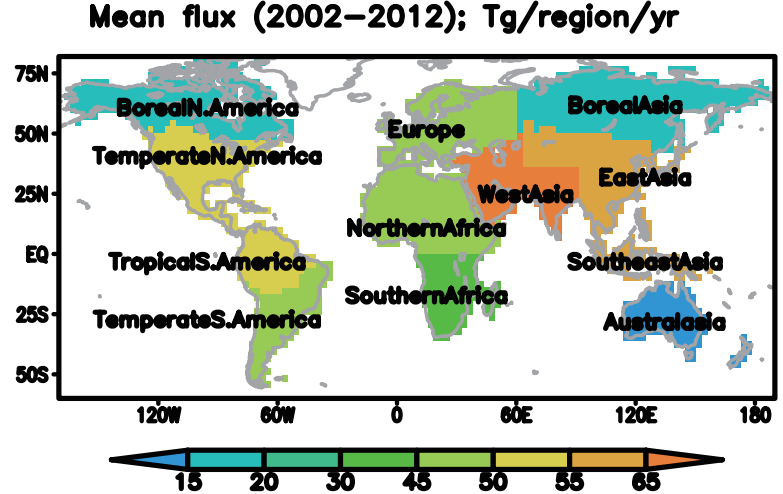

Fig. 7. A map of 12 aggregated regions for discussion of regional emissions. Mean fluxes for the whole period of inversion are shown as the shaded background.

of $39 \pm 7 \mathrm{Tg} \mathrm{yr}^{-1}$ during $1998-2002$ and $46 \pm 8 \mathrm{Tg} \mathrm{yr}^{-1}$ in 2009/2010 for China alone, taking into account for nonseasonal or anthropogenic sources without rice fields. Thompson et al. (2015) estimated East Asian $\mathrm{CH}_{4}$ emissions to be 44.4 and $51.9 \mathrm{Tg} \mathrm{yr}^{-1}$ averaged over 2000-2005 and 2006-2011, respectively. Our results suggest that the economic activity or energy use proxies, as currently employed for developing emission inventories (Janssens-Maenhout et al. 2012), does not apply linearly to $\mathrm{CH}_{4}$ emission inventory creation for decadal time periods. Factors such as the implementation of green technology, improved fuel combustion efficiency or change in chemical composition of fuel are important in explaining why the emissions do not scale with economic growth.

\subsection{Interannual variations in estimated fluxes}

Figure 8 shows the time evolution of annual mean $\mathrm{CH}_{4}$ emissions from the 12 aggregated regions as estimated by the ensemble of 7 inversions. Similar to the behavior in the seasonal cycle, the IAV in the posterior emissions follows that a priori, with some added information from the inversion. Our results agree broadly with previous inverse modeling in that $\mathrm{CH}_{4}$ emissions in Tropical South America increased in 2007 and 2010 (Houweling et al. 2014) and that Tropical regions are the dominant driver for IAVs in $\mathrm{CH}_{4}$ emissions (Patra et al. 2011; Bousquet et al. 2011). Since regions are defined differently among studies, this makes detailed comparisons between studies difficult. The ACTM based inversions estimated a $\mathrm{CH}_{4}$ emission increase of $\sim 5 \mathrm{Tg} \mathrm{yr}^{-1}$ in 2006 for the Southeast Asia region (Fig. 8i). Only a fraction 
Table 1. Ranges of regional total $\mathrm{CH}_{4}$ emissions from the 6 inversions based on the EDGAR42FT (anthropogenic) and VISIT (wetland and rice) emissions. The $\mathrm{CH}_{4} \mathrm{ctl}$ inversion is not included here for simplicity, since it shows excursions in emission magnitudes for some regions (ref. Fig. 8; cyan and horizontal grey lines), although the a posteriori global totals fall within the range given here.

\begin{tabular}{lcccc}
\hline \multicolumn{1}{c}{ Region name } & \multicolumn{4}{c}{$\mathrm{CH}_{4}$ emissions (units: $\mathrm{Tg} \mathrm{yr}^{-1}$ ) } \\
& \multicolumn{2}{c}{$2002-2006$} & \multicolumn{2}{c}{$2008-2012$} \\
\cline { 2 - 5 } & Prior & Posterior & Prior & Posterior \\
\hline Boreal N. America & $17.4-17.5$ & $19.5-20.0$ & $17.3-17.4$ & $19.6-20.2$ \\
Temperate N. America & $53.0-53.7$ & $49.5-50.3$ & $53.2-54.3$ & $47.9-50.2$ \\
Tropical S. America & $51.8-52.5$ & $48.4-48.7$ & $50.5-52.3$ & $50.0-53.9$ \\
Temperate S. America & $41.4-43.9$ & $46.8-47.9$ & $41.1-45.6$ & $50.6-53.6$ \\
Northern Africa & $46.0-47.6$ & $46.3-47.8$ & $45.1-48.4$ & $47.8-52.1$ \\
Southern Africa & $28.9-29.5$ & $31.4-32.2$ & $28.1-29.6$ & $31.9-33.8$ \\
Boreal Asia & $15.7-16.8$ & $16.7-17.3$ & $15.1-18.0$ & $16.3-17.7$ \\
South Asia & $72.1-75.8$ & $66.5-69.3$ & $73.3-83.2$ & $68.1-74.2$ \\
East Asia & $66.9-75.4$ & $59.2-62.2$ & $67.4-91.9$ & $66.1-74.4$ \\
Southeast Asia & $64.1-66.1$ & $58.1-59.3$ & $61.3-66.9$ & $61.1-66.4$ \\
Australasia & $9.3-9.7$ & $8.3-8.7$ & $8.4-9.2$ & $7.7-8.7$ \\
Europe & $45.5-47.0$ & $48.2-50.8$ & $45.0-47.5$ & $45.9-49.8$ \\
Global Land* & $514-534$ & $505-509$ & $508-561$ & $524-545$ \\
\hline
\end{tabular}

*the minimum and maximum in the last row are not the totals of regional minimum and maximum values of regional emissions, but are the lowest and highest values global total emissions. Thus the 12 regional minima-maxima do not add up to that for the global totals.

$(68 \%)$ of this IAV comes from the use of IAV in a priori emissions from the wetlands (VISIT terrestrial ecosystem models) and biomass burning (GFED). However, the inversion case $\mathrm{CH}_{4}$ ctl, which did not include any IAV in the a priori emissions, has brought out a similar 2006 increase, which is quite consistent with other inversions that had IAV in the prior emissions.

The emission IAVs in East Asia and South Asia (Figs. 8f, h, respectively) are presumably caused by an increase in anthropogenic activities as suggested by EDGAR42FT, in which the main causes of a priori $\mathrm{CH}_{4}$ emission increase are fugitive (coal burning) and enteric fermentation. As per Food and Agricultural Organization (FAO) statistics, the non dairy cattle and cow population in Asia increased monotonically by 15 $\%$ between 2002 and 2012, from a total of 356 million heads in 2002 (FAOSTAT 2015; see also Fig. S2). The inversions also suggested a systematic increase in $\mathrm{CH}_{4}$ emission from the South American continent, which was not present in most of the a priori emission cases, except for $\mathrm{CH}_{4} \mathrm{e} 42$. According to the FAO statistics, the cattle and cow population increased by $14 \%$ in South America during 2001-2004, and remained steady at 313 million heads during 2004-
2012. Similarly a sustained increase in cattle and cow population is also seen in Africa, by $22 \%$ during 2002-2012 (from 190 to 231 million heads), which could explain the emission increase estimated in the Northern Africa region by the inversion. Although we cannot attribute specific causes to the estimated changes in emissions due to the simplistic design of the inversion system, our inversion results along with the FAO statistics and the EDGAR inventories strongly suggest an increase of biogenic emissions in the tropical and SH land in the 2nd half of the 2000s. An outlook on the separation of $\mathrm{CH}_{4}$ emission types using $\mathrm{C}$ and $\mathrm{H}$ isotopologues is given in Section 3.8.

Another interesting outcome of the ensemble inversion cases is that the regional bias in a priori emissions of one region apparently affects the a posteriori emissions of several other regions in the same semi-hemisphere $(\mathrm{NH} / \mathrm{SH}$ extratropics and tropics). We find the strongest decrease in a posteriori emissions compared to the a priori from Europe, Temperate and Boreal North America in inversion case $\mathrm{CH}_{4} \mathrm{e} 42$, which has strongest increase in emission during 2005-2012 for East and South Asia. These couplings in the estimated emissions also have a cascading effect in emission estimation of Northern 

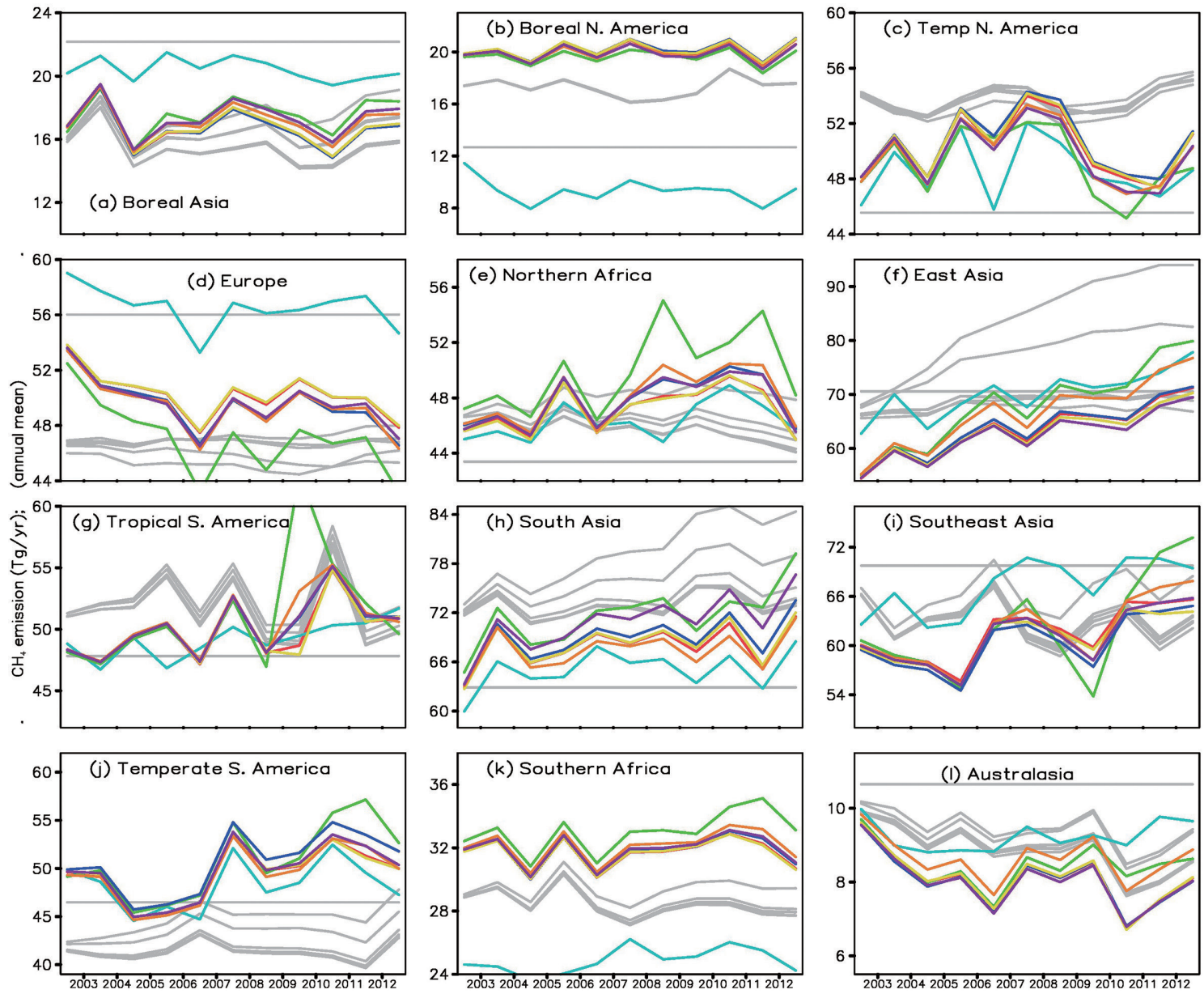

Fig. 8. $\mathrm{CH}_{4}$ emissions for the 12 aggregated regions as estimated by 7 different inversion cases $\left(\mathrm{CH}_{4}\right.$ ags - red, $\mathrm{CH}_{4} 42$ - green, $\mathrm{CH}_{4}$ enf - blue, $\mathrm{CH}_{4}$ fix - yellow, $\mathrm{CH}_{4}$ fug - orange, $\mathrm{CH}_{4}$ ong - purple and $\mathrm{CH}_{4}$ ctl - cyan). The seasonal (3-monthly time intervals) anomalies in $\mathrm{CH}_{4}$ emissions are depicted in Fig. S1 (Supplementary figure).

Africa (propagated by a dipole with the European emissions) and as far as the regions in the SH (Fig. 8; green lines in bottom row). In a parallel effort, we use the ACTM forward model and $\mathrm{CO}_{2}$ measurements at 74 sites to estimate fluxes from 54 land regions. Our $\mathrm{CO}_{2}$ inversion results suggest an increased 'residual land sink' over East Asia, Boreal Asia and Boreal North America. By analogy of our $\mathrm{CH}_{4}$ inversion ensemble, we consider that the estimated increased land sink is very likely to be an artifact of excessive fossil fuel $\mathrm{CO}_{2}$ emission given by the inventory emission databases (e.g., EDGAR42FT 2013). The inversion for $\mathrm{CO}_{2}$ optimizes total $\mathrm{CO}_{2}$ fluxes, thus the land sink is the residual of the total minus the 'known' fossil fuel emission. Conventional $\mathrm{CO}_{2}$ and $\mathrm{CH}_{4}$ inverse models do not include a priori emission ensemble, instead focusing on other input parameters such as observational data networks, forward model parameters and inversion methodology (Rayner et al. 1999; Peylin et al. 2013; Bergamaschi et al. 2013; Bousquet et al. 2011; Houweling et al. 2014). Thus our results suggest that a priori emission trends should be treated with extra caution for separating regional emissions and sinks of long-lived species (lifetime of months and longer, e.g., including carbon monoxide). The shorter lived species (lifetime of days, e.g., nitrogen oxides) emitted from one region do not affect directly mole fractions of another sub-continental scale region.

\subsection{Seasonal cycle of $\mathrm{CH}_{4}$ emissions}

The seasonal cycle in $\mathrm{CH}_{4}$ emission is mainly 

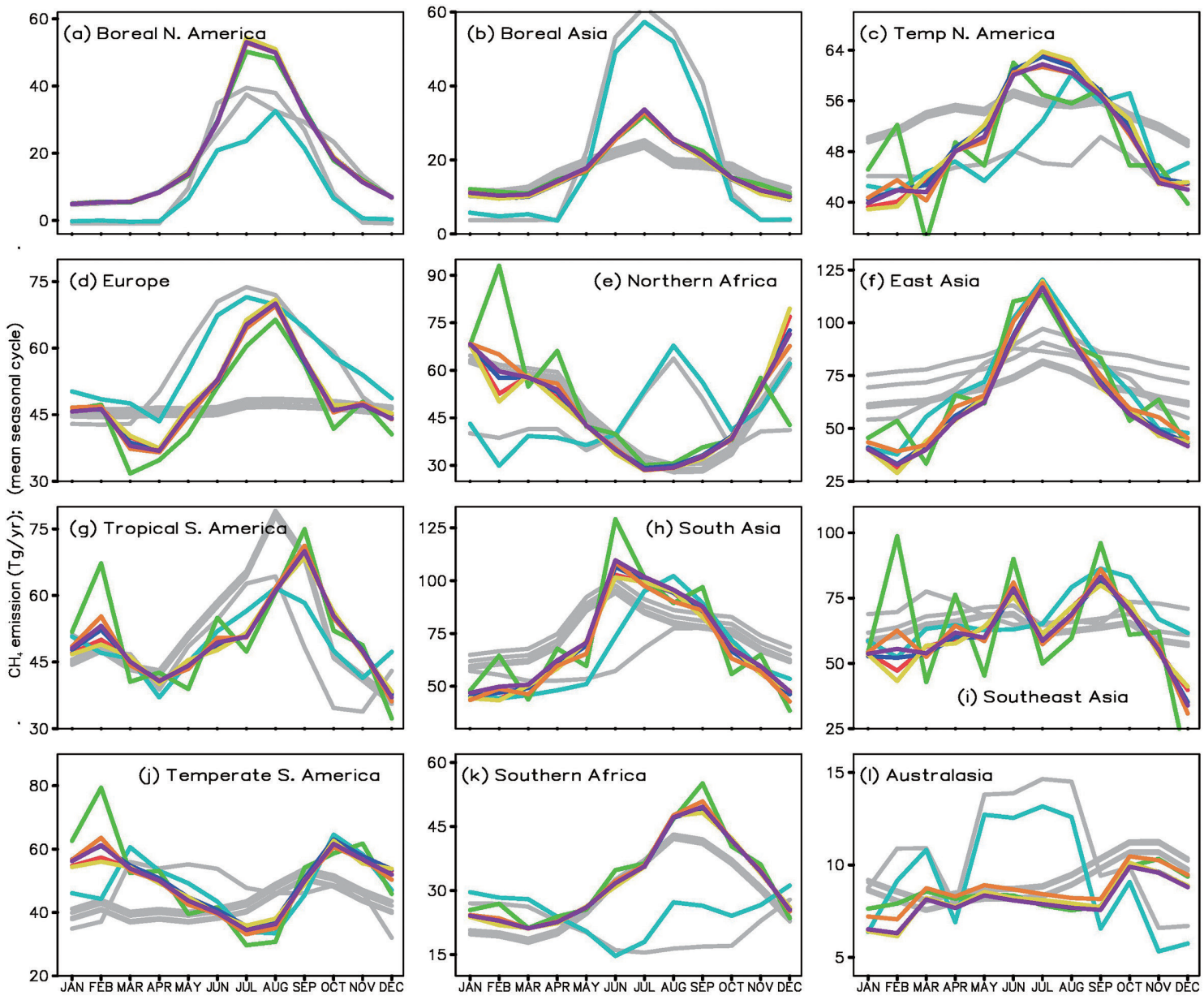

Fig. 9. Seasonal cycle of $\mathrm{CH}_{4}$ emissions as estimated by the inversions (coloured lines; $\mathrm{CH}_{4}$ ags - red, $\mathrm{CH}_{4} 42$ green, $\mathrm{CH}_{4}$ enf - blue, $\mathrm{CH}_{4} \mathrm{fix}$ - yellow, $\mathrm{CH}_{4}$ fug - orange, $\mathrm{CH}_{4}$ ong - purple and $\mathrm{CH}_{4}$ ctl - cyan) for different a priori emission scenarios (grey lines). We show all the 7 inversion results, although the results of only $\mathrm{CH}_{4} \mathrm{e} 42$ and $\mathrm{CH}_{4} \mathrm{ctl}$ are clearly different from the other 5 cases (lines generally hidden under $\mathrm{CH}_{4} \mathrm{ong}$ ).

controlled by changes in biogenic activity, typically with maximum intensity in hot and humid conditions, and thus is one of the most important components in understanding and controlling $\mathrm{CH}_{4}$ cycling in the Earth's environment. Figure 9 shows seasonal variations in $\mathrm{CH}_{4}$ emissions as estimated by the bottom-up (a priori) and top-down (a posteriori) methods. Emission seasonality differs substantially between the $\mathrm{CH}_{4} \mathrm{ctl}$ case and the other 6 a priori ensemble cases for most of the 12 analysis regions. The seasonality differences between $\mathrm{CH}_{4} \mathrm{ctl}$ and other a priori cases arise from emissions due to wetlands, rice paddies and biomass burning because the anthropogenic emissions do not contain seasonal variation. In general, the VISIT model simulated emission seasonality follows surface temperature and soil wetness, whereas, Yan et al. (2009) inventory-based emission map $\left(\mathrm{CH}_{4} \mathrm{ctl}\right)$ has a delayed seasonal maximum in emissions of rice paddies in the South Asia region by taking into account the timing of rice planting, growing phase and harvesting, and field based flux measurements (Fig. 9h). The shape of both sets of seasonal cycle phase and amplitude come closer after inversion; $\mathrm{CH}_{4} \mathrm{ctl}$ is shifted to an earlier peak by 2 month from August to June and the seasonal cycle amplitude increased for all.

For the Boreal Asia region, GISS wetland emissions $\left(\mathrm{CH}_{4} \mathrm{ctl}\right)$ produced a much greater amplitude of seasonal cycle in a narrower time window than that simulated by the VISIT model (Fig. 9b). Unfortu- 
Table 2. ACTM simulated (using a posteriori emissions) $\mathrm{CH}_{4}$ interhemispheric gradients (units: ppb) in the altitude range 0-4 km compared with HIPPO QCLS measurements for all 5 campaigns. Approximate simulation results using a priori emissions are given in parenthesis.

\begin{tabular}{lccccc}
\hline Obs./Model & $\begin{array}{c}\text { HIPPO-1 } \\
\text { (January 2009) }\end{array}$ & $\begin{array}{c}\text { HIPPO-2 } \\
\text { (November 2009) }\end{array}$ & $\begin{array}{c}\text { HIPPO-3 } \\
\text { (Mar-Apr 2010) }\end{array}$ & $\begin{array}{c}\text { HIPPO-4 } \\
\text { (Jun-Jul 2011) }\end{array}$ & $\begin{array}{c}\text { HIPPO-5 } \\
\text { (Aug-Sep 2011) }\end{array}$ \\
\hline $\mathrm{CH}_{4}$ QCLS & 108.6 & 89.7 & 115.8 & 63.8 & 69.5 \\
$\mathrm{CH}_{4}$ ags & $110.3(111)$ & $87.5(82)$ & $116.2(132)$ & $61.0(75)$ & $61.9(56)$ \\
$\mathrm{CH}_{4}$ e42 & $111.3(121)$ & $86.1(93)$ & $117.2(147)$ & $63.1(87)$ & $62.4(65)$ \\
$\mathrm{CH}_{4}$ efm & $110.1(110)$ & $87.0(82)$ & $115.8(132)$ & $60.9(75)$ & $61.6(55)$ \\
$\mathrm{CH}_{4}$ fix & $110.3(110)$ & $87.6(82)$ & $116.2(131)$ & $60.9(75)$ & $61.9(55)$ \\
$\mathrm{CH}_{4}$ fug & $111.1(116)$ & $87.3(87)$ & $117.4(140)$ & $62.1(81)$ & $62.4(61)$ \\
$\mathrm{CH}_{4}$ ong & $110.6(113)$ & $87.6(85)$ & $116.6(136)$ & $61.6(78)$ & $62.1(58)$ \\
$\mathrm{CH}_{4}$ ctl & $116.8(109)$ & $92.6(88)$ & $123.9(118)$ & $62.7(66)$ & $64.9(68)$ \\
\hline
\end{tabular}

nately, the inversion model did not add much to our knowledge in deciding the correctness of either of these emission fields. Similarly, agreement between $\mathrm{CH}_{4} \mathrm{ctl}$ and other inversion cases did not improve for Northern Africa and Australasia. This is primarily because the surface measurement network does not cover these land regions sufficiently (Fig. 5b). We find that the peak emission over Southern Africa for the $\mathrm{CH}_{4} \mathrm{ctl}$ case is developed so as to be in line with those suggested by the VISIT wetlands and GFED biomass burning emissions (other cases). The August peak for the $\mathrm{CH}_{4}$ ctl case increases to $32 \mathrm{Tg} \mathrm{yr}^{-1}$ if the a priori emission uncertainty is increased to $100 \%$ of the regional emission. Further tuning of the inverse modeling parameters $\left(C_{D}\right.$ and $\left.C_{S_{0}}\right)$ can produce better agreement between the inversion cases. However, we treated all regions uniformly to avoid the modeler's intuitions biasing the results. The VISIT wetland emissions did not show much seasonality for Europe, but the inverse model produced a seasonal cycle amplitude and phase that is more comparable to that present in the GISS database. Similarly the seasonal cycles after inversion are in close agreement for $\mathrm{CH}_{4} \mathrm{ctl}$ and 6 other inversions for North America and East Asia where the observational constraints are relatively strong (Fig. 5). These results highlight the need for measurements over continents to constrain regional emissions. In addition, CTMs has to be run at higher spatial resolution for better representation of continental sites, which is not the case with ACTM $\mathrm{T} 42$ resolution.

\subsection{Validation using independent atmospheric data}

One of the most difficult tasks for the inverse modeling community is deriving a robust metric for validating estimates of emissions and sinks. A common approach is to compare an independent set of measurements to the simulations (or assimilated fields) using a posteriori emissions. We show summary statistics of model and observed interhemispheric (IH) $\mathrm{CH}_{4}$ gradients during the five HIPPO campaigns in Table 2 and Fig. S3. The IH gradients are calculated as the difference between the average $\mathrm{NH}-\mathrm{SH} \mathrm{CH}_{4}$ in the altitude range of $0-3 \mathrm{~km}$. Measurements over the Central Pacific are only used in this analysis for testing the validity of the zonalmean inverted emissions in simulating meridional mole fraction gradients. In general, IH gradients are greatest in the winter-spring (HIPPO-1 and HIPPO-3) when $\mathrm{OH}$ concentrations are smallest in the $\mathrm{NH}$, and the $\mathrm{IH}$ gradient reduces through the summer as $\mathrm{CH}_{4}$ loss by tropospheric $\mathrm{OH}$ rises in the NH (HIPPO4). This decrease in $\mathrm{CH}_{4}$ mole fraction is observed despite the seasonal increase in $\mathrm{CH}_{4}$ emissions from natural wetlands and rice cultivation in the NH (Fig. 9). $\mathrm{CH}_{4}$ starts to build up in the $\mathrm{NH}$ starting from autumn (HIPPO-5 and HIPPO-2).

The comparison results show that ACTM-HIPPO differences are typically below 3 ppb for 4 of the 5 HIPPO campaigns, with the exception of HIPPO-5 when the model-observation differences are generally above $7 \mathrm{ppb}$ (except for $\mathrm{CH}_{4} \mathrm{ctl}$ ). The a priori case $\mathrm{CH}_{4} \mathrm{e} 42$ generally produced the highest model-observation mismatches, up to $31 \mathrm{ppb}$ for HIPPO-3. This suggests that the $\mathrm{CH}_{4}$ emissions in the $\mathrm{NH}$ are overestimated in the a priori case $\mathrm{CH}_{4} \mathrm{e} 42$. Since most of the emission increase during 2004-2012 came from fugitive emissions over China, the relatively large ACTM-HIPPO concentration differences indicate an overestimation in EDGAR42FT (2013). The poor simulation of the IH gradient by ACTM for HIPPO-5 suggests that either the emissions need to be higher during the summer-autumn months in the $\mathrm{NH}$ or the loss due to $\mathrm{OH}$ is overestimated. Note that the a priori 

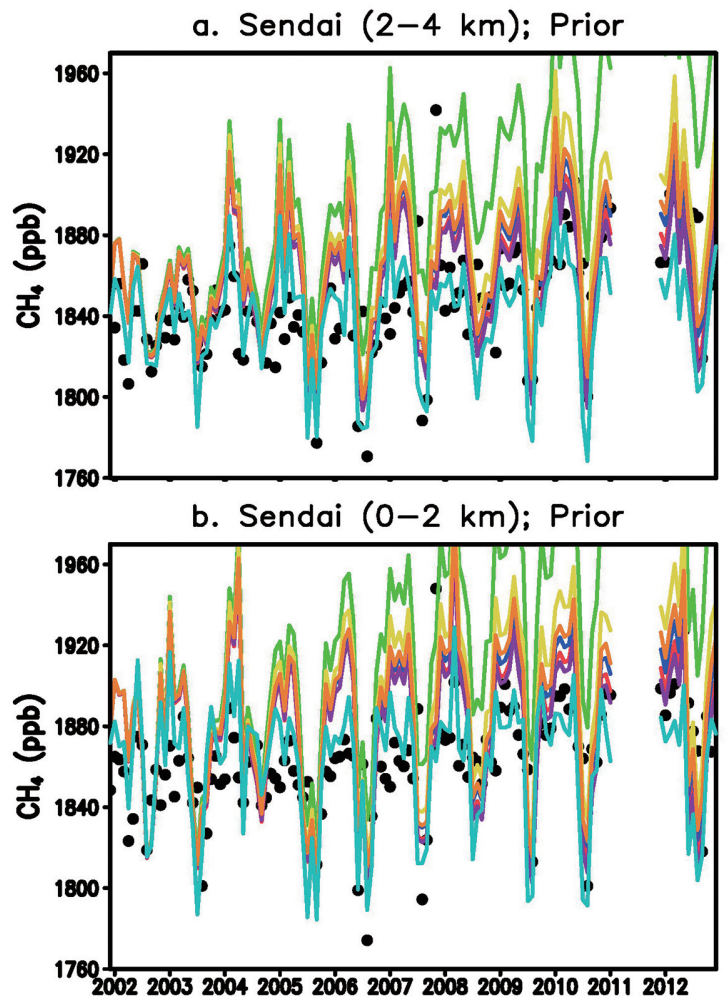

c. Sendai $(2-4 \mathrm{~km})$; Poste

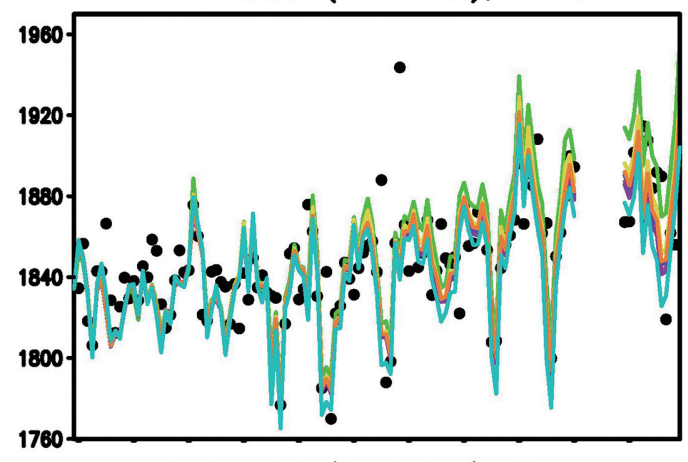

d. Sendai $(0-2 \mathrm{~km})$; Poste

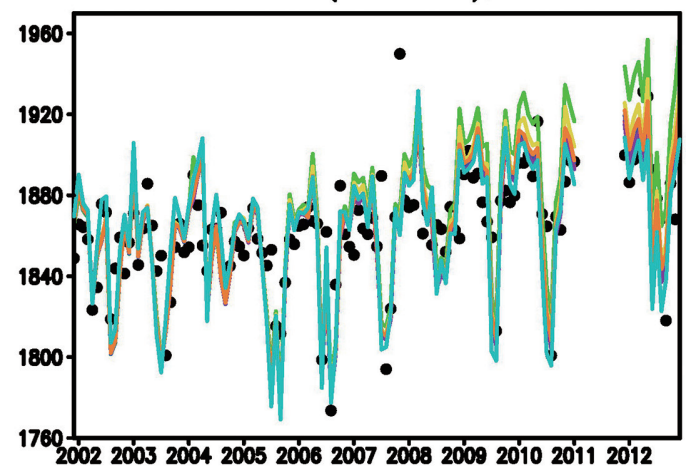

Fig. 10. $\mathrm{CH}_{4}$ over Sendai, Japan in altitude range of 2-4 km (top) and 0-2 km (down). Measurements are taken from Tohoku University (circle) and ACTM simulations for 6 inversion cases (lines; colours correspond to the emissions in Fig. 6) are shown.

simulation of $\mathrm{CH}_{4}$ ctl was in better agreement (within $3 \mathrm{ppb}$ ) with HIPPO measurements compared to that using a posteriori emission (difference as great as 8 ppb for HIPPO-1 and HIPPO-3). This is because the $\mathrm{CH}_{4}$ ctl inversion produced greater $\mathrm{CH}_{4}$ emissions in the latitude band of $25-50^{\circ} \mathrm{N}$. In contrast, $\mathrm{CH}_{4}$ ags a posteriori emissions are greater in the latitude band of $30^{\circ} \mathrm{S}-\mathrm{Eq}$ compared to a priori emissions and thus the large model IH gradients during HIPPO-3 and HIPPO-4. This suggests that inversions using 39 surface sites provide somewhat limited constrain on accurately describing the fine details in latitudinal distribution of $\mathrm{CH}_{4}$ emissions.

In addition to the spatial/meridional emission distribution, estimation of the time evolution of emissions is an integral part of understanding the mechanisms of $\mathrm{CH}_{4}$ emissions due to natural climate variability and human activity. Figure 10 shows the time series of $\mathrm{CH}_{4}$ over Sendai, Japan. The simulated mole fractions calculated with a posteriori emissions agree with the measured values within $0.3 \%(5 \mathrm{ppb})$ for indi- vidual years, except for the $\mathrm{CH}_{4} \mathrm{e} 42$ case. The vertical gradients are also well simulated for 2002-2012 (not shown) with typical model-observation differences lower than $20 \mathrm{ppb}$. More interestingly we find that the simulated $\mathrm{CH}_{4}$ seasonal cycle amplitude has increased from $\sim 40 \mathrm{ppb}$ (peak to trough) in 2002-2003 to $\sim 60$ ppb during 2011-2012. The seasonal cycle amplitude is overestimated by ACTM simulation using a priori emissions, and largest overestimation is seen for the $\mathrm{CH}_{4} \mathrm{e} 42$ case, suggesting that the impact of the emission increase in China on $\mathrm{CH}_{4}$ concentration seasonality might be observable over Japan. ACTM simulations using a posteriori emissions better match the observed seasonal cycles (Figs. 10c, d) and are indistinguishable from each other. These comparisons clearly indicate that the $\mathrm{CH}_{4} \mathrm{e} 42$ inversion case still overestimates emissions of $\mathrm{CH}_{4}$ from the East Asia region. Thus our best estimated emission increase is 7-8 $\mathrm{Tg} \mathrm{yr}^{-1}$ over the periods of 2002-2006 and 2008-2012. Note here that the a posteriori uncertainty was about $22 \mathrm{Tg} \mathrm{yr}^{-1}$ for the East Asia region, which 
does not truly reflect the quality of mean a posteriori fluxes, and the quality of the mean fluxes is better verified (within $10 \mathrm{Tg} \mathrm{yr}^{-1}$ ) using independent aircraft measurements.

Given the similarities in increase of anthropogenic $\mathrm{CO}_{2}$ and $\mathrm{CH}_{4}$ emissions, we briefly discuss implications our $\mathrm{CH}_{4}$ inversion results for $\mathrm{CO}_{2}$ inverse modeling. Despite the differences in emission sectors, global total anthropogenic $\mathrm{CO}_{2}$ and $\mathrm{CH}_{4}$ emissions increased by $16 \%$ and $10 \%$, respectively, between the periods of 2002-2006 and 2008-2012 (EDGAR42FT 2013). In the case of $\mathrm{CO}_{2}$ inversions, residual (terrestrial biosphere) fluxes for land regions are estimated assuming that our knowledge of anthropogenic emission due to fossil fuel burning and cement production is accurate. This implies that if the regional $\mathrm{CO}_{2}$ anthropogenic emission is overestimated, the terrestrial biosphere will appear as a lower source or increased sink of $\mathrm{CO}_{2}$ by inverse modeling. However, the $\mathrm{CH}_{4}$ inversion emission validation results clearly suggest an overestimation of anthropogenic emissions in EDGAR42FT (2013). We propose that the enhanced residual $\mathrm{CO}_{2}$ sinks in the East Asian terrestrial biosphere are likely to be estimated by inverse modeling of atmospheric $\mathrm{CO}_{2}$, if correction to anthropogenic $\mathrm{CO}_{2}$ emission increase rate is not applied before inversion. As an example, the increase in $\mathrm{CH}_{4}$ emission by $19 \mathrm{Tg} \mathrm{yr}^{-1}$ by EDGAR42FT was reduced to $7-8 \mathrm{Tg} \mathrm{yr}^{-1}$ by our inversion for the East Asia region.

Large fractions of total $\mathrm{CO}_{2}$ and $\mathrm{CH}_{4}$ emission increases from China are attributed to fossil-fuel burning alone, i.e., public electricity and heat production $(48 \%)$ and fugitive from solid (32\%), respectively, according to the EDGAR42 during the periods between 2001-2004 and 2005-2008. By analogy, we may expect less than $50 \%$ of the anthropogenic $\mathrm{CO}_{2}$ emission increase of $1.0 \mathrm{PgC} \mathrm{yr}^{-1}$ estimated by EDGAR42FT between the periods of 2002-2006 and 2008-2012. Thus $\mathrm{CO}_{2}$ inversions using EDGAR42FT anthropogenic emission as a priori would estimate an increased terrestrial biosphere sink over East Asia between the periods of 2002-2006 and 2008-2012. We propose that the large terrestrial $\mathrm{CO}_{2}$ sink of $1.56 \mathrm{PgC}^{-1}$ over Asia estimated in recent inverse modeling studies (e.g., Zhang et al. 2014) is partly an artifact of greater anthropogenic emission estimated by the inventory emissions for China. Interestingly, if the anthropogenic $\mathrm{CO}_{2}$ emissions from China grew at half the rate of what is projected by emission inventories, total emissions from China would have overtaken $\mathrm{CO}_{2}$ emission from the United States in 2009 (1.45
$\left.\mathrm{PgC} \mathrm{yr}^{-1}\right)$, not in $2006\left(1.59 \mathrm{PgC} \mathrm{yr}^{-1}\right)$ as suggested in EDGAR42FT (see also Gregg et al. 2008).

\subsection{Time-latitude distribution of the atmospheric growth rate}

Figure 11 shows the growth rate of $\mathrm{CH}_{4}$ as measured and simulated at 21 background sites out of the 39 sites used in the inversion (case $\mathrm{CH}_{4}$ ags). This reconfirms that use of the same sites in the inversion and subsequent forward simulations do not necessarily constitute a perfect model condition, i.e., when the same transport model is used before and after inversion. Due to insufficient degrees of freedom in the inversion system in the case of $\mathrm{CH}_{4} \mathrm{e} 42$, the inverted fluxes failed to represent the time evolution of global total $\mathrm{CH}_{4}$ emissions for simulating $\mathrm{CH}_{4}$ growth rates that are consistent with observations

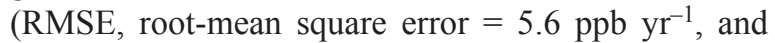
mean bias $3.5 \mathrm{ppb} \mathrm{yr}^{-1}$; not shown). Growth rates are calculated by taking the time-derivative of longterm trends of $\mathrm{CH}_{4}$ time series calculated with a curve fitting method (Nakazawa et al. 1997). However, the a posteriori RMSE and bias were reduced significantly compared to the a priori emission case of $\mathrm{CH}_{4} \mathrm{e} 42(8.3$

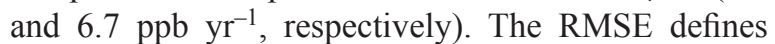
how well the model captures the observed interannual variations in the growth rate and bias indicates model-observation agreement between overall trends during the period of analysis (2002-2012). Notably, the RMSE and mean bias in $\mathrm{CH}_{4}$ growth rates simulated using $\mathrm{CH}_{4}$ ags emissions are 3.6 and $0.44 \mathrm{ppb}$ $\mathrm{yr}^{-1}$, respectively, better than those in the a priori emission case, 5.7 and $-1.6 \mathrm{ppb} \mathrm{yr}^{-1}$ (Fig. 11). Low reduction of $\mathrm{CH}_{4}$ growth rate RMSE $(\sim 37 \%)$ after inversion is likely to be caused by the use of cyclostationary regional pulse function.

Figure 11 suggests that the anomalous positive growth rate in 2002-2003 and negative growth rates in 2004-2005 originated in the tropics and the NH. However, the recent positive anomalies in growth rates in 2007 and 2010 are more likely to have originated in the $\mathrm{SH}$ and the tropics. An increase in anthropogenic emission is also suggested by the EDGAR42FT inventory (Figs. 6c, d; case $\mathrm{CH}_{4} \mathrm{e} 42$ ), which is consistent with our inversion results for emission trends over South America and South Asia. The rate of global total fire emissions decreased slightly from $16 \mathrm{Tg} \mathrm{yr}^{-1}$ in 2002-2006 to about $13 \mathrm{Tg}$ $\mathrm{yr}^{-1}$ in 2007-2012 (van der Werf et al. 2010; updated results). The inversion flux analysis does not allow us to ascertain what type of activities have caused the increase in emissions. However, the University of 


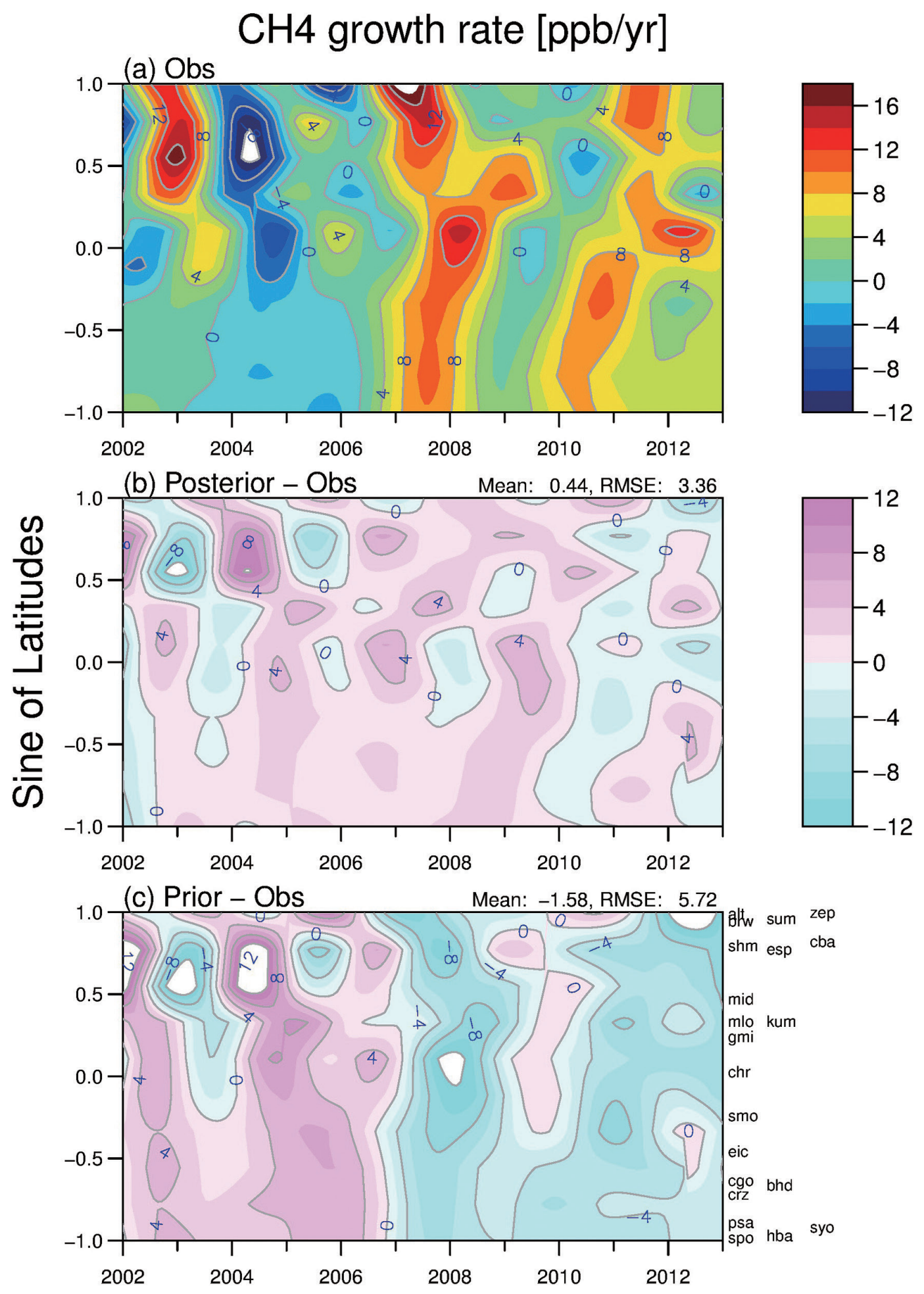

Fig. 11. Observed and simulated $\mathrm{CH}_{4}$ growth rates for 2002-2012, based on selected 21 marine sites of the 39 sites used in inversions. Simulated cases using $\mathrm{CH}_{4}$ ags a priori and a posteriori emissions are depicted in the bottom and middle panels, respectively, using a common colour scale (light blue to pink). Sites used in making these plots are indicated on the right side of the bottom panel, placed according to their location latitudes. 
Colorado, INSTAAR (White and Vaughn 2015) has observed a decrease (more negative value of the relative ratio of ${ }^{13} \mathrm{C}$ to ${ }^{12} \mathrm{C}$, i.e., towards lighter $\mathrm{CH}_{4}$ ) in stable carbon isotopic ratios of atmospheric $\mathrm{CH}_{4}\left({ }^{13} \mathrm{C}\right.$ $\mathrm{CH}_{4}$ ) since about 2008, suggesting an increase in $\mathrm{CH}_{4}$ production through microbial activity, such as enteric fermentation (as discussed earlier using FAO statistics of cattle and cow population) and wetlands. However, our a priori emission cases including wetland emission variations using VISIT terrestrial ecosystem model did not suggest any increase (Ito and Inatomi 2012). The estimated $\mathrm{CH}_{4}$ emissions from enteric fermentation globally increased from $89 \mathrm{Tg} \mathrm{yr}^{-1}$ in 2002 to $99 \mathrm{Tg} \mathrm{yr}^{-1}$ in 2009 (FAOSTAT, 2015; 10 $\mathrm{Tg} \mathrm{yr}^{-1}$ increase is also seen in EDGAR42FT for the period 2000-2010). This increase in emission corresponds to global non-dairy cattle population increase from 1056 million in 2002 to 1160 million in 2012 (approximately, $10 \%$ ), with majority of contributions coming from Asia (15\%), South America (14\%) and Africa (22\%).

\section{Conclusions}

$\mathrm{A} \mathrm{CH}_{4}$ inverse model was developed using ACTM by introducing a few modifications to our $\mathrm{CO}_{2}$ inversion system for estimation of emissions from 53 land regions globally at monthly time intervals for the period 2002-2012. The new system is also applicable to other species, such as $\mathrm{N}_{2} \mathrm{O}$, Halocarbons, with low reactivity in the atmosphere and reasonably well balanced global total a priori sources and sinks estimates. We have used interannually varying meteorology (JRA-25 nudged to AGCM) for simulating atmospheric $\mathrm{CH}_{4}$ and regional basis function simulations were simulated using one year of meteorology (2009). Model simulations did not consider interannual variation in $\mathrm{OH}$ radical concentration, although the temperature dependent reaction rates were calculated. We prepared 7 cases of a priori emission scenarios and utilized them for checking the performance of the inverse model to constrain regional, semi-hemispheric and global total $\mathrm{CH}_{4}$ emissions. We used $\mathrm{CH}_{4}$ mole fraction measurements from 39 sites (37 NOAA and 2 JMA) in the period of 2001-2013.

The a posteriori $\mathrm{CH}_{4}$ emissions are in general agreement with previous studies. Global total emissions are estimated to be 505-506 $\mathrm{Tg} \mathrm{yr}^{-1}$ in 2002 2006 and 524-532 in 2008-2012 (range based on 6 inversion cases). The renewed growth in atmospheric $\mathrm{CH}_{4}$ burden since 2007 was triggered by emissions from tropical Asia and southern South America. Using the statistics from Food and Agriculture Organiza- tion of the United Nations (FAOSTAT) and a preliminary analysis of carbon isotopic ratio of atmospheric $\mathrm{CH}_{4}\left({ }^{13} \mathrm{CH}_{4}\right)$, we conclude that the renewed growth rate in 2007 and its sustenance is caused by $\mathrm{CH}_{4}$ sources from enteric fermentation. On contrary to the large anthropogenic emissions from China in the EDGAR42FT emission inventory $\left(\sim 17 \mathrm{Tg} \mathrm{yr}^{-1}\right.$ during the 2002-2006 and 2008-2012), our results suggest a much lower increase rate of $7-8 \mathrm{Tg} \mathrm{yr}^{-1}$. The inventory emissions are calculated based on the economic activity and country level energy consumption statistics, which are then applied with emission factors for various species. Given that the EDGAR42FT database also show rapid increase in fossil fuel $\mathrm{CO}_{2}$ emissions from China, and residual terrestrial fluxes in inverse modeling are estimated with an assumption that fossil fuel $\mathrm{CO}_{2}$ emissions are accurately known (e.g., Rayner et al. 1999; Peylin et al. 2013), we propose that the $\mathrm{CO}_{2}$ residual sink over East Asia estimated by inverse modeling is likely to be overestimated for the recent years because of overestimation of $\mathrm{CO}_{2}$ emissions from fossil fuel burning. Further efforts are needed to resolve such ambiguity in estimation of $\mathrm{CO}_{2}$ fluxes by inverse modeling. Artifacts of an overestimation in anthropogenic $\mathrm{CO}_{2}$ emission on $\mathrm{CO}_{2}$ inversion of terrestrial biosphere sources and sinks are discussed in Section 3.7.

One of the major deficiencies of this inverse model setup is poor constrain on the seasonal cycle of $\mathrm{CH}_{4}$ emissions at the regional scale. There were, however, signs of closer agreement between the a posteriori emissions for $\mathrm{CH}_{4} \mathrm{ctl}$ and other 6 ensemble cases. This is mainly because of the sparse measurement network practically used for the inversion (39 sites). In the future, we would also like to realistically introduce interannual variations in loss of $\mathrm{CH}_{4}$ by $\mathrm{OH}$ chemistry and $\mathrm{Cl}$ in marine boundary layer - both of which are poorly known presently.

\section{Acknowledgments}

This work is supported by JSPS/KAKENHI Kiban-A (grant\#22241008), MEXT Arctic GRENE (ID 5) and MoE Environment Research and Technology Development Fund (2-1401). We acknowledge the support of personnel working at the experimental sites and those supporting the model development. All the model results (input and output) as well as the data used in plotting are available unconditionally from the lead author, and measurements are available from http://ds.data.jma.go.jp/gmd/wdegg and http://www.esrl. noaa.gov/gmd/dv/ftpdata.html for scientific use with reciprocity agreement. We thank both the reviewers 
for insightful comments and helpful suggestions for improving the quality of this paper.

\section{Appendix}

Details of 39 measurement sites used in the inversion. Most (37) sites are operated by the GMD/NOAA and two (YON and MNM) are operated by JMA. Root mean-square errors of model-observation differences are also given for ACTM simulations using a priori and a posteriori emissions $\left(\mathrm{CH}_{4}\right.$ ags case).

\begin{tabular}{|c|c|c|c|c|c|c|}
\hline \multirow{2}{*}{$\begin{array}{l}\text { Sl. } \\
\text { No. }\end{array}$} & \multirow{2}{*}{$\begin{array}{l}\text { WDCGG } \\
\text { name }\end{array}$} & \multirow{2}{*}{$\begin{array}{l}\text { Latitude } \\
\left(^{\circ}\right)\end{array}$} & \multirow{2}{*}{$\begin{array}{l}\text { Longitude } \\
\qquad\left({ }^{\circ} \mathrm{E}\right)\end{array}$} & \multirow{2}{*}{$\begin{array}{l}\text { Altitude } \\
\text { (m) }\end{array}$} & \multicolumn{2}{|c|}{$\begin{array}{c}\text { Model- } \\
\text { Observed } \mathrm{CH}_{4}\end{array}$} \\
\hline & & & & & $\begin{array}{c}\text { A } \\
\text { priori }\end{array}$ & $\begin{array}{c}\text { A } \\
\text { posteriori }\end{array}$ \\
\hline 1 & alt482n00 & 82.5 & 297.5 & 210 & 22.9 & 8.9 \\
\hline 2 & $\operatorname{asc} 107 \mathrm{~s} 00$ & -7.9 & 345.6 & 54 & 11.5 & 5.1 \\
\hline 3 & ask123n00 & 23.3 & 5.6 & 2710 & 20.8 & 7.4 \\
\hline 41 & bhd541s00 & -41.4 & 174.9 & 85 & 44.6 & 28.4 \\
\hline 51 & bmw432n00 & 32.3 & 295.1 & 30 & 23.0 & 12.4 \\
\hline 61 & brw471n00 & 71.3 & 203.4 & 11 & 20.5 & 12.0 \\
\hline 7 & cba455n00 & 55.2 & 197.3 & 25 & 21.8 & 9.8 \\
\hline 8 & cgo540s00 & -40.7 & 144.7 & 94 & 14.8 & 5.6 \\
\hline 9 & chr501n00 & 1.7 & 202.8 & 3 & 22.4 & 10.5 \\
\hline 10 & crz146s00 & -46.5 & 51.9 & 120 & 15.0 & 5.8 \\
\hline 11 & eic $327 \mathrm{~s} 00$ & -27.1 & 250.6 & 50 & 13.7 & 4.9 \\
\hline 12 & esp449n00 & 49.4 & 233.5 & 39 & 25.2 & 10.5 \\
\hline 13 & gmi513n00 & 13.4 & 144.8 & 2 & 21.7 & 11.8 \\
\hline 141 & hba775s00 & -75.6 & 333.5 & 33 & 15.6 & 5.9 \\
\hline 151 & hun646n00 & 47.0 & 16.7 & 248 & 24.2 & 18.0 \\
\hline $16 \mathrm{i}$ & ice $663 \mathrm{n} 00$ & 63.4 & 339.7 & 100 & 24.2 & 10.8 \\
\hline $17 \mathrm{i}$ & izo128n00 & 28.3 & 343.5 & 2367 & 18.5 & 8.1 \\
\hline 181 & key425ocn & 25.7 & 279.8 & 3 & 27.2 & 12.6 \\
\hline 191 & kum519n00 & 19.5 & 205.2 & 3 & 25.4 & 10.0 \\
\hline 201 & mhd653lnd & 53.3 & 350.1 & 8 & 23.4 & 11.5 \\
\hline 211 & $\operatorname{mid} 528 \mathrm{n} 00$ & 28.2 & 182.6 & 8 & 23.5 & 9.7 \\
\hline 221 & mlo519n00 & 19.5 & 204.4 & 3397 & 28.0 & 11.9 \\
\hline 231 & nwr440n01 & 40.1 & 254.4 & 3523 & 20.7 & 8.8 \\
\hline 241 & pal667n00 & 68.0 & 24.1 & 560 & 27.8 & 15.9 \\
\hline 251 & psa764s00 & -64.9 & 296.0 & 10 & 14.7 & 5.5 \\
\hline 261 & rpb413n00 & 13.2 & 300.6 & 45 & 21.0 & 8.4 \\
\hline 27 & sey104s00 & -4.7 & 55.2 & 7 & 24.5 & 13.4 \\
\hline 28 & $\operatorname{shm} 452 \mathrm{n} 00$ & 52.7 & 174.1 & 40 & 21.5 & 10.9 \\
\hline 29 & smo514s00 & -14.2 & 189.4 & 42 & 16.5 & 7.2 \\
\hline 30 & spo789s00 & -87.0 & 335.2 & 2810 & 14.9 & 5.3 \\
\hline 31 & sum672n00 & 72.6 & 321.5 & 3238 & 21.5 & 7.8 \\
\hline 32 & syo769s00 & -69.0 & 39.6 & 16 & 14.5 & 5.3 \\
\hline 33 & uta439n00 & 39.9 & 246.3 & 1320 & 33.5 & 13.9 \\
\hline 34 & uum244n00 & 44.5 & 111.1 & 914 & 28.7 & 16.3 \\
\hline 35 & wis $631 \mathrm{n} 00$ & 31.1 & 34.9 & 400 & 24.8 & 11.2 \\
\hline 36 & wlg236n00 & 36.3 & 100.9 & 3810 & 22.7 & 11.6 \\
\hline 37 & zep678n00 & 78.9 & 11.9 & 475 & 24.2 & 9.9 \\
\hline 381 & $\mathrm{mnm} 224 \mathrm{nhr}$ & 24.3 & 154.0 & 8 & 27.1 & 10.1 \\
\hline $39 y$ & yon224nhr & 24.5 & 123.0 & 30 & 26.1 & 12.1 \\
\hline
\end{tabular}

\section{References}

Alberto, M. C. R., R. Wassmanna, R. J. Buresha, J. R. Quiltya, T. Q. Correa, Jr., J. M. Sandroa, and C. A.
R. Centenoa, 2014: Measuring methane flux from irrigated rice fields by eddy covariance method using open-path gas analyzer. Field Crops Res., 160, 12-21.

Aoki, S., T. Nakazawa, S. Murayama, and S. Kawaguchi, 1992: Measurements of atmospheric methane at the Japanese Antarctic Station, Syowa. Tellus B, 44, 273-281.

Bange, H. W., T. G. Bell, M., M. Cornejo, A. Freing, G. Uher, R. C. Upstill-Goddard, and G. Zhang, 2009: MEMENTO: a proposal to develop a database of marine nitrous oxide and methane measurements. Environ. Chem., 6, 195-197.

Bergamaschi, P., S. Houweling, A. Segers, M. Krol, C. Frankenberg, R. A. Scheepmaker, E. Dlugokencky, S. C. Wofsy, E. A. Kort, C. Sweeney, T. Schuck, C. Brenninkmeijer, H. Chen, V. Beck, and C. Gerbig, 2013: Atmospheric $\mathrm{CH}_{4}$ in the first decade of the 21 st century: Inverse modeling analysis using SCIAMACHY satellite retrievals and NOAA surface measurements. J. Geophys. Res., 118, 7350-7369.

Bousquet, P., P. Ciais, J. B. Miller, E. J. Dlugokencky, D. A. Hauglustaine, C. Prigent, G. R. van der Werf, P. Peylin, E.-G. Brunke, C. Carouge, R. L. Langenfelds, J. Lathière, F. Papa, M. Ramonet, M. Schmidt, L. P. Steele, S. C. Tyler, and J. White, 2006: Contribution of anthropogenic and natural sources to atmospheric methane variability. Nature, 443, 439-443.

Bousquet, P., B. Ringeval, I. Pison, E. J. Dlugokencky, E.-G. Brunke, C. Carouge, F. Chevallier, A. FortemsCheiney, C. Frankenberg, D. A. Hauglustaine, P. B. Krummel, R. L. Langenfelds, M. Ramonet, M. Schmidt, L. P. Steele, S. Szopa, C. Yver, N. Viovy, and P. Ciais, 2011: Source attribution of the changes in atmospheric methane for 2006-2008. Atmos. Chem. Phys., 11, 3689-3700.

Cunnold, D. M., L. P. Steele, P. J. Fraser, P. G. Simmonds, R. G. Prinn, R. F. Weiss, L. W. Porter, S. O'Doherty, R. L. Langenfelds, P. B. Krummel, H. J. Wang, L. Emmons, X. X. Tie, and E. J. Dlugokencky, 2002: In situ measurements of atmospheric methane at GAGE/AGAGE sites during 1985-2000 and resulting source inferences. J. Geophys. Res., 107, 4225, doi:10.1029/2001JD001226.

Dlugokencky, E. J., S. Houweling, L. Bruhwiler, K. A. Masarie, P. M. Lang, J. B. Miller, and P. P. Tans, 2003: Atmospheric methane levels off: Temporary pause or a new steady-state? Geophys. Res. Lett., 30, 1992, doi:10.1029/2003GL018126.

Dlugokencky, E. J., R. C. Myers, P. M. Lang, K. A. Masarie, A. Crotwell, K. W. Thoning, B. D. Hall, J. W. Elkins, and L. P. Steele, 2005: Conversion of NOAA atmospheric dry air $\mathrm{CH}_{4}$ mole fractions to a gravimetrically prepared standard scale. J. Geophys. Res., 110, D18306, doi:10.1029/2005JD006035.

Dlugokencky, E. J., L. M. P. Bruhwiler, J. W. C. White, L. K. Emmons, P. C. Novelli, S. A. Montzka, K. A. 
Masarie, P. M. Lang, A. M. Crotwell, J. B. Miller, and L. V. Gatti, 2009: Observational constraints on recent increases in the atmospheric $\mathrm{CH}_{4}$ burden. Geophys. Res. Lett., 36, L18803, doi:10.1029/2009GL039780.

EDGAR42FT, 2013: Global emissions EDGAR v4.2 FT2010. [Available at http://edgar.jrc.ec.europa.eu/ overview.php? $\mathrm{v}=42 \mathrm{FT} 2010$.]

Etiope, G., and A. V. Milkov, 2004: A new estimate of global methane flux from onshore and shallow submarine mud volcanoes to the atmosphere. Environ. Geol., 46, 997-1002.

FAOSTAT, 2015: Statistics devision. Food and Agriculture Organization of the United Nations. [Available at http://faostat3.fao.org/download/Q/QL/E.]

Fung, I., J. John, J. Lerner, E. Matthews, M. Prather, L. P. Steele, and P. J. Fraser, 1991: Three-dimensional model synthesis of the global methane cycle. $J$. Geophys. Res., 96, 13033-13065.

Ghosh, A., P. K. Patra, K. Ishijima, T. Umezawa, A. Ito, D. M. Etheridge, S. Sugawara, K. Kawamura, J. B. Miller, E. J. Dlugokencky, P. B. Krummel, P. J. Fraser, L. P. Steele, R. L. Langenfelds, C. M. Trudinger, J. W. C. White, B. Vaughn, T. Saeki, S. Aoki, and T. Nakazawa, 2015: Variations in global methane sources and sinks during 1910-2010. Atmos. Chem. Phys., 15, 2595-2615.

Gregg, J. S., R. J. Andres, and G. Marland, 2008: China: Emissions pattern of the world leader in $\mathrm{CO}_{2}$ emissions from fossil fuel consumption and cement production. Geophys. Res. Lett., 35, L08806, doi:10.1029/2007GL032887.

Hein, R., P. J. Crutzen, and M. Heimann, 1997: An inverse modeling approach to investigate the global atmospheric methane cycle. Global Biogeochem. Cycles, 11, 43-76.

Houweling, S., M. Krol, P. Bergamaschi, C. Frankenberg, E. J. Dlugokencky, I. Morino, J. Notholt, V. Sherlock, D. Wunch, V. Beck, C. Gerbig, H. Chen, E. A. Kort, T. Röckmann, and I. Aben, 2014: A multi-year methane inversion using SCIAMACHY, accounting for systematic errors using TCCON measurements. Atmos. Chem. Phys., 14, 3991-4012.

Ito, A., and M. Inatomi, 2012: Use of a process-based model for assessing the methane budgets of global terrestrial ecosystems and evaluation of uncertainty. Biogeosciences, 9, 759-773.

Janssens-Maenhout, G, F. Dentener, J. van Aardenne, S. Monni, V. Pagliari, L. Orlandini, Z. Klimont, J. Kurokawa, H. Akimoto, T. Ohara, R. Wankmueller, B. Battye, D. Grano, A. Zuber, and T. Keating, 2012: EDGAR-HTAP: A harmonized gridded air pollution emission dataset based on national inventories. JRC Scientific and Technical Reports, EUR report No. EUR 25299-2012, European Commission Joint Research Center Institute for Environment Sustainability, Italy.
Khalil, M. A. K., and R. A. Rasmussen, 1983: Decreasing trend of methane: Unpredictability of future concentrations. Chemosphere, 26, 803-814.

Kirschke, S., P. Bousquet, P. Ciais, M. Saunois, J. G. Canadell, E. J. Dlugokencky, P. Bergamaschi, D. Bergmann, D. R. Blake, L. Bruhwiler, P. Cameron-Smith, S. Castaldi, F. Chevallier, L. Feng, A. Fraser, M. Heimann, E. L. Hodson, S. Houweling, B. Josse, P. J. Fraser, P. B. Krummel, J.-F. Lamarque, R. L. Langenfelds, C. Le Quéré, V. Naik, S. O'Doherty, P. I. Palmer, I. Pison, D. Plummer, B. Poulter, R. G. Prinn, M. Rigby, B. Ringeval, M. Santini, M. Schmidt, D. T. Shindell, I. J. Simpson, R. Spahni, L. P. Steele, S. A. Strode, K. Sudo, S. Szopa, G. R. van der Werf, A. Voulgarakis, M. van Weele, R. F. Weiss, J. E. Williams, and G. Zeng, 2013: Three decades of global methane sources and sinks. Nat. Geosci., 6, 813-823.

Lassey, K. R., W. Allan, and S. E. M. Fletcher, 2011: Seasonal inter-relationships in atmospheric methane and companion $\delta^{13} \mathrm{C}$ values: Effects of sinks and sources. Tellus B, 63, 287-301.

Liu, Z., D. Guan, W. Wei, S. J. Davis, P. Ciais, J. Bai, S. Peng, Q. Zhang, K. Hubacek, G. Marland, R. J. Andres, D. Crawford-Brown, J. Lin, H. Zhao, C. Hong, T. A. Boden, K. Feng, G. P. Peters, F. Xi, J. Liu, Y. Li, Y. Zhao, N. Zeng, and K. He, 2015: Reduced carbon emission estimates from fossil fuel combustion and cement production in China. Nature, 524, 335-338.

Matthews, E., and I. Fung, 1987: Methane emissions from natural wetlands: Global distribution, area, and environmental characteristics of sources. Global Biogeochem. Cycles, 1, 61-86.

Montzka, S. A., M. Krol, E. J. Dlugokencky, B. Hall, P. Joeckel, and J. Lelieveld, 2011: Small interannual variability of global atmospheric hydroxyl. Science, 331, 67-69.

Nakazawa, T., M. Ishizawa, K. Higuchi, and N. B. A. Trivett, 1997: Two curve fitting methods applied to $\mathrm{CO}_{2}$ flask data. Environmetrics, 8, 197-218.

Onogi, K., J. Tsutsui, H. Koide, M. Sakamoto, S. Kobayashi, H. Hatsushika, T. Matsumoto, N. Yamazaki, H. Kamahori, K. Takahashi, S. Kadokura, K. Wada, K. Kato, R. Oyama, T. Ose, N. Mannoji, and R. Taira, 2007: The JRA-25 Reanalysis. J. Meteor. Soc. Japan, 85, 369-432.

Patra, P. K., S. Maksyutov, Y. Sasano, H. Nakajima, G. Inoue and T. Nakazawa, 2003: An evaluation of $\mathrm{CO}_{2}$ observations with Solar Occultation FTS for Inclined-Orbit Satellite sensor for surface source inversion. J. Geophys. Res., 108, 4759, doi:10.1029/2003JD003661.

Patra, P. K., M. Takigawa, K. Ishijima, B.-C. Choi, D. Cunnold, E. J. Dlugokencky, P. Fraser, A. J. Gomez-Pelaez, T.-Y. Goo, J.-S. Kim, P. Krummel, R. 
Langenfelds, F. Meinhardt, H. Mukai, S. O’Doherty, R. G. Prinn, P. Simmonds, P. Steele, Y. Tohjima, K. Tsuboi, K. Uhse, R. Weiss, D. Worthy, and T. Nakazawa, 2009: Growth rate, seasonal, synoptic, diurnal variations and budget of methane in lower atmosphere. J. Meteor. Soc. Japan, 87, 635-663.

Patra, P. K., S. Houweling, M. Krol, P. Bousquet, D. Belikov, D. Bergmann, H. Bian, P. Cameron-Smith, M. P. Chipperfield, K. D. Corbin, A. FortemsCheiney, A. Fraser, E. Gloor, P. Hess, A. Ito, S. R. Kawa, R. M. Law, Z. Loh, S. Maksyutov, L. Meng, P. I. Palmer, R. G. Prinn, M. Rigby, R. Saito, and C. Wilson, 2011: TransCom model simulations of $\mathrm{CH}_{4}$ and related species: Linking transport, surface flux and chemical loss with $\mathrm{CH}_{4}$ variability in the troposphere and lower stratosphere. Atmos. Chem. Phys., 11, 12813-12837.

Patra, P. K., M. C. Krol, S. A. Montzka, T. Arnold, E. L. Atlas, B. R. Lintner, B. B. Stephens, B. Xiang, J. W. Elkins, P. J. Fraser, A. Ghosh, E. J. Hintsa, D. F. Hurst, K. Ishijima, P. B. Krummel, B. R. Miller, K. Miyazaki, F. L. Moore, J. Mühle, S. O’Doherty, R. G. Prinn, L. P. Steele, M. Takigawa, H. J. Wang, R. F. Weiss, S. C. Wofsy, and D. Young, 2014: Observational evidence for interhemispheric hydroxyl parity. Nature, 513, 219-223.

Peylin, P., R. M. Law, K. R. Gurney, F. Chevallier, A. Jacobson, T. Maki, Y. Niwa, P. K. Patra, W. Peters, P. J. Rayner, C. Rödenbeck, I. T. van der Laan-Luijkx, and X. Zhang, 2013: Global Atmospheric Carbon Budget: results from an ensemble of atmospheric $\mathrm{CO}_{2}$ inversions. Biogeosciences, 10, 6699-5360.

Rayner, P. J., I. G. Enting, R. J. Francey, and R. Langenfelds, 1999: Reconstructing the recent carbon cycle from atmospheric $\mathrm{CO}_{2}, \delta^{13} \mathrm{C}$ and $\mathrm{O}_{2} / \mathrm{N}_{2}$ observations. Tellus B, 51, 213-232.

Rigby, M., R. G. Prinn, P. J. Fraser, P. G. Simmonds, R. L. Langenfelds, J. Huang, D. M. Cunnold, L. P. Steele, P. B. Krummel, R. F. Weiss, S. O'Doherty, P. K. Salameh, H. J. Wang, C. M. Harth, J. Muhle, and L. W. Porter, 2008: Renewed growth of atmospheric methane. Geophys. Res. Lett., 35, L22805, doi:10.1029/2008GL036037.

Ringeval, B., N. de Noblet-Ducoudre, P. Ciais, P. Bousquet, C. Prigent, F. Papa, and W. B. Rossow, 2010: An attemp to quantify the impact of changes in wetland extent on methane emissions at the seasonal and interannual time scales. Global Biogeochem. Cycles, 24, GB2003, doi:10/1029/2008GB003354.

Sander, S. P., D. M. Golden, M. J. Kurylo, G. K. Moortgat, H. Keller-Rudek, P. H. Wine, A. R. Ravishankara, C. E. Kolb, M. J. Molina, B. J. Finlayson-Pitts, R. E. Huie, and V. L. Orkin, 2006: Chemical Kinetics and Photochemical Data for Use in Atmospheric Studies. Evaluation Number 15. Jet Propulsion Laboratory, California Institute of Technology, CA, USA, 552 pp.
Schneising, O., M. Buchwitz, M. Reuter, J. Heymann, H. Bovensmann, and J. P. Burrows, 2011: Long-term analysis of carbon dioxide and methane column-averaged mole fractions retrieved from SCIAMACHY. Atmos. Chem. Phys., 11, 2863-2880.

Spivakovski, C. M., J. A. Logan, S. A. Montzka, Y. J. Balkanski, M. Foreman-Fowler, D. B. A. Jones, L. W. Horowitz, A. C. Fusco, C. A. M. Brenninkmeijer, M. J. Prather, S. C. Wofsy, and M. B. McElroy, 2000: Three dimensional climatological distribution of tropospheric OH: Update and evaluation. J. Geophys. Res., 105, 8931-8980.

Steele, L. P., E. J. Dlugokencky, P. M. Lang, P. P. Tans, R. C. Martin, and K. A. Masarie, 1992: Slowing down of the global accumulation of atmospheric methane during the 1980s. Nature, 358, 313-316.

Takigawa, M., M. Takahashi, and H. Akiyoshi, 1999: Simulation of ozone and other chemical species using a Center for Climate System Research/National Institute for Environmental Studies atmospheric GCM with coupled stratospheric chemistry. J. Geophys. Res., 104, 14003-14018.

Thompson, R. L., A. Stohl, L. X. Zhou, E. Dlugokencky, Y. Fukuyama, Y. Tohjima, S.-Y. Kim, H. Lee, E. G. Nisbet, R. E. Fisher, D. Lowry, R. F. Weiss, R. G. Prinn, S. O'Doherty, D. Young, and J. W. C. White, 2015: Methane emissions in East Asia for 2000-2011 estimated using an atmospheric Bayesian inversion. $J$. Geophys. Res., 120, 4532-4369.

Tohjima, Y., M. Kubo, C. Minejima, H. Mukai, H. Tanimoto, A. Ganshin, S. Maksyutov, K. Katsumata, T. Machida, and K. Kita, 2014: Temporal changes in the emissions of $\mathrm{CH}_{4}$ and $\mathrm{CO}$ from China estimated from $\mathrm{CH}_{4} / \mathrm{CO}_{2}$ and $\mathrm{CO} / \mathrm{CO}_{2}$ correlations observed at Hateruma Island. Atmos. Chem. Phys., 14, 16631677.

Umezawa, T., D. Goto, S. Aoki, K. Ishijima, P. K. Patra, S. Sugawara, S. Morimoto, and T. Nakazawa, 2014: Variations of tropospheric methane over Japan during 1988-2010. Tellus B, 66, 23837, doi:10.3402/tellusb. v66.23837.

UNEP, 2011: Near-term climate protection and clean air benefits: Actions for controlling short-lived climate forcers. A UNEP Synthesis Report, United Nations Environment Programme, Kenya, Africa, 78 pp.

van der Werf, G. R., J. T. Randerson, L. Giglio, G. J. Collatz, M. Mu, P. S. Kasibhatla, D. C. Morton, R. S. DeFries, Y. Jin, and T. T. van Leeuwen, 2010: Global fire emissions and the contribution of deforestation, savanna, forest, agricultural, and peat fires (19972009). Atmos. Chem. Phys., 10, 11707-11735.

Wada, A., H. Matsueda, Y. Sawa, K. Tsuboi, and S. Okubo, 2011: Seasonal variation of enhancement ratios of trace gases observed over 10 years in the western North Pacific. Atmos. Environ., 45, 2129-2137.

Wang, J. M., J. G. Murphy, J. A. Geddes, C. L. Winsbor- 
ough, N. Basiliko, and S. C. Thomas, 2013: Methane fluxes measured by eddy covariance and static chamber techniques at a temperate forest in central Ontario, Canada. Biogeosciences, 10, 4371-4382.

White, J. W. C., and B. H. Vaughn, 2015: Stable Isotopic composition of atmospheric methane $\left({ }^{13} \mathrm{C}\right)$. The NOAA ESRL Carbon Cycle Cooperative Global Air Sampling Network, 1998-2013, Ver. 2015-04-24. University of Colorado, Institute of Arctic Alpine Research (INSTAAR). [Available at: ftp://ftp.cmdl. noaa.gov/ccg/ch4c13/flask/event/.]

Wofsy, S. C., 2011: HIAPER Pole-to-Pole Observations (HIPPO): Fine-grained, global-scale measurements of climatically important atmospheric gases and aerosols. Philos. Trans. Roy. Soc. A, 369, 2073-2086.

Yan, X., H. Akiyama, K. Yagi, and H. Akimoto, 2009: Global estimations of the inventory and mitigation potential of methane emissions from rice cultivation conducted using the 2006 intergovernmental panel on climate change guidelines. Global Biogeochem.
Cycles, 23, GB2002, doi:10.1029/2008GB003299.

Yoshida, Y., Y. Ota, N. Eguchi, N. Kikuchi, K. Nobuta, H. Tran, I. Morino, and T. Yokota, 2011: Retrieval algorithm for $\mathrm{CO}_{2}$ and $\mathrm{CH}_{4}$ column abundances from short-wavelength infrared spectral observations by the Greenhouse gases observing satellite. Atmos. Meas. Tech., 4, 717-734.

Zhang, H. F., B. Z. Chen, I. T. van der Laan-Luijk, T. Machida, H. Matsueda, Y. Sawa, Y. Fukuyama, R. Langenfelds, M. van der Schoot, G. Xu, J. W. Yan, M. L. Cheng, L. X. Zhou, P. P. Tans, and W. Peters, 2014: Estimating Asian terrestrial carbon fluxes from CONTRAIL aircraft and surface $\mathrm{CO}_{2}$ observations for the period 2006-2010. Atmos. Chem. Phys., 14, 5807-5824.

Zhou, L. X., J. Tang, Y. P. Wen, J. Li, P. Yan, and X. Zhang, 2003: The impact of local winds and long-range transport on the continuous carbon dioxide record at Mount Waliguan, China. Tellus B, 55, 145-158. 